\title{
Do all students understand the same message? High school teachers' use of non-literal expressions
}

by

Munogaree Richards

A research dissertation submitted to Victoria University of Wellington in partial fulfilment of the requirements for the degree of Master of Arts in Applied Linguistics

Victoria University of Wellington

Te Whare Wānanga o te Ūpoko o te Ika a Māui. 
(This page was intentionally left blank) 


\section{Abstract}

Studies about neuro-typical, second language (L2) learners' understanding of nonliteral (e.g., metaphoric) expressions and its relationship to academic tasks are numerous. However, there are few studies (Kerber \& Grunwell, 1997; Littlemore, Chen, Koester \& Barnden, 2011, Lazar, Warr-Leeper, Nicholson, \& Johnson, 1989) about the awareness that teachers have of their use of figurative language / non-literal expressions and the potentially problematic nature of their use of these expressions. Parallel findings are seen in the field of autism research where much of the literature on autism has highlighted the tendency for students who have been given a diagnosis of Asperger Syndrome (AS), a high functioning variant of autism, to take non-literal expressions literally. A primary aim of this study was therefore to explore to what extent (if at all) mainstream high-school teachers' use of non-literal language poses obstacles for comprehension with AS-students in their classroom settings. A secondary aim of this study was to explore teachers' awareness and knowledge about their nonliteral language use with AS-students. Nine teachers and eighteen students from the same year group were participants, of which nine students had a diagnosis of AS and nine were neuro-typical students (NS). The participants were students and teachers from high-schools in Wellington, New Zealand who all spoke English as their first language (L1). A sample of episodes of the teachers' in-class use of non-literal language, representing a range of established expressions (for example, idioms) as well as episodes of more 'creative' non-literal use of language (including irony), were selected to serve as prompts in interviews with the teachers. These episodes served to elicit the teachers' reflections on the reasons for why they resorted to those figures of speech. They also served as prompts in stimulated recall interviews with the ASstudents and their neuro-typical peers, where these participants were asked to give their interpretations of their teachers' utterances. Overall, the results from this task suggested that the AS-students found it harder than their neuro-typical peers to recognize their teachers' intended meanings. This finding, however, needs to be interpreted with caution, because the AS-students also seemed less inclined to offer the kind of explanations (for example, paraphrasing what the teacher had said) that provide clear evidence of comprehension. Interestingly, most of the AS-students demonstrated metacognitive strategies in the detection of their teachers' creative use of metaphor and their teachers' use of irony. However, this alone did not always result in a correct 
interpretation. When shown the instances of non-literal utterances they had used in class, most of the teachers reported motives for using these, but these were predominantly motives that emerged during real-time classroom interaction. Most of the teachers expressed surprise at the extent to which they (the teachers) used nonliteral language in interactions with their students. Strategies to support student interpretation of figurative language are addressed together with recommendations for further research. It is intended that this study will be of interest to teachers and clinicians who support students with a diagnosis of Asperger Syndrome.

Key words: Figurative language, metaphor, irony, comprehension, Asperger Syndrome, teacher cognition, language awareness, reflective practice. 


\section{Acknowledgement}

Associate Professor Frank Boers from the School of Linguistics and Applied Language Studies, Faculty of Humanities and Social Sciences, Victoria University of Wellington for his expert guidance and encouragement

The students and teachers for their invaluable contribution to the study

My family and friends for their interest and support throughout this academic journey 
(This page was intentionally left blank) 


\section{Table of Contents}

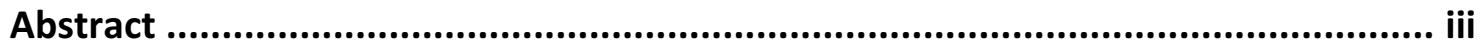

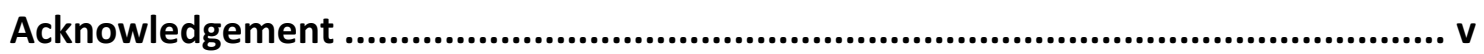

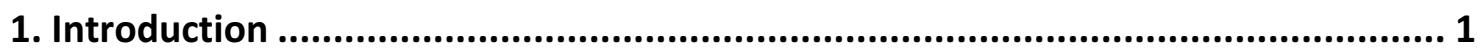

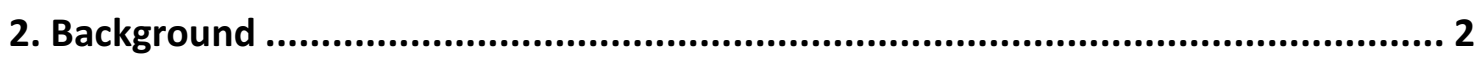

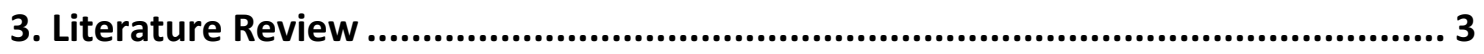

3.1. Frequency and relevance of idiomatic expressions .................................................... 4

3.2. Idiom interpretation and Asperger Syndrome .......................................................... 5

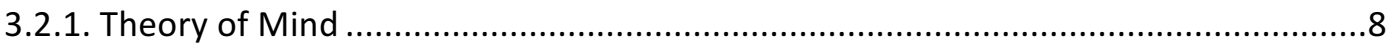

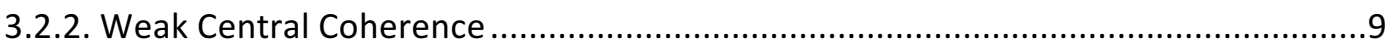

3.3. Neurological evidence for idiom comprehension difficulties ...................................... 10

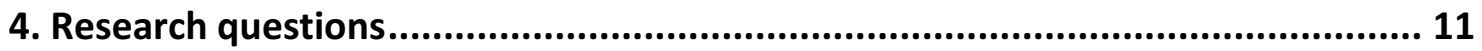

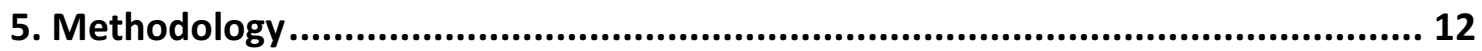

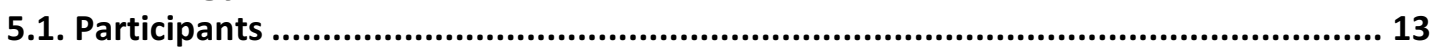

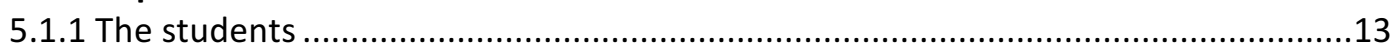

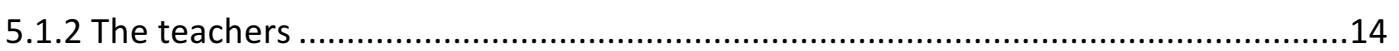

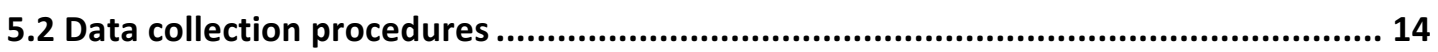

5.2.1 Classroom observations and collection of expressions. ........................................14

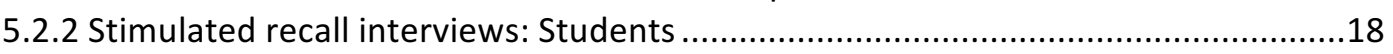

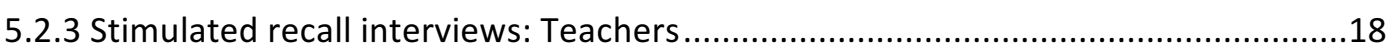

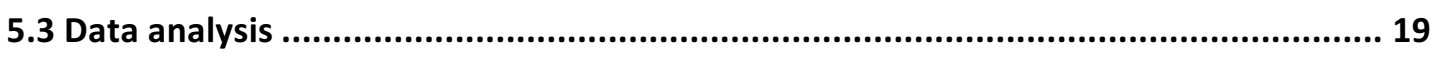

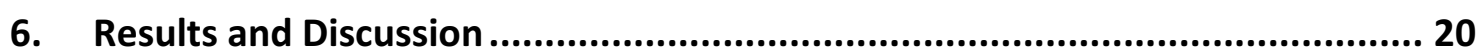

6.1 The students' comprehension of their teachers' expressions ..................................... 20

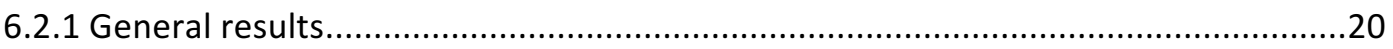

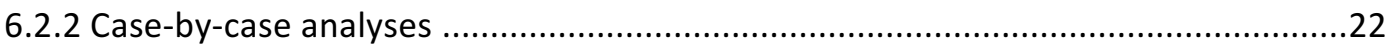

6.2.3 Expressions that posed particular problems for students ......................................34

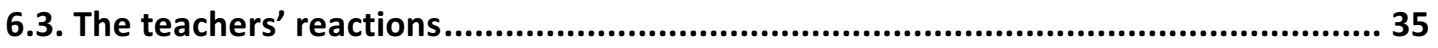

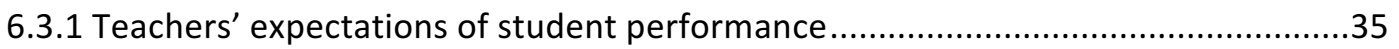

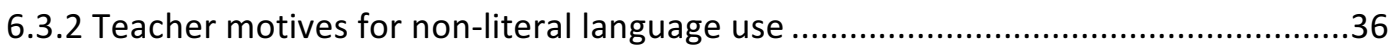

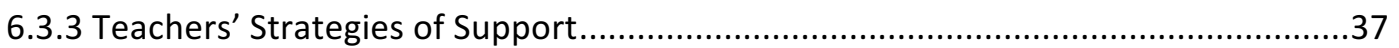

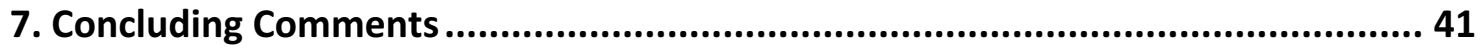

7.1 Strategies to support students in the classroom ...................................................... 42

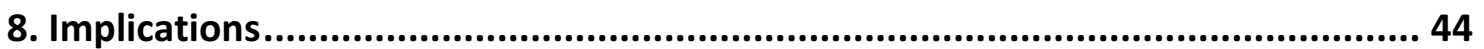

9. Limitations and recommendations for further research .................................. 44

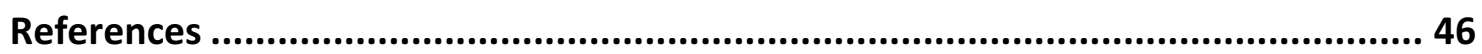

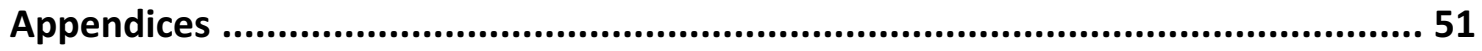

School information sheet ........................................................................................... 52

Parent information sheet (for students diagnosed with Asperger Syndrome) .................. 54

Parent information sheet (for neuro-typical students)..................................................... 56

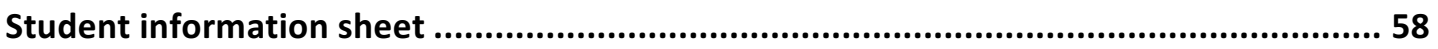


(This page was intentionally left blank) 


\section{Introduction}

Several studies have shown that $\mathrm{L} 2$ learners experience comprehension problems when they encounter non-literal expressions (metaphoric and/or metonymic expressions), even if these expressions consist of words whose basic meanings they are familiar with (Martinez \& Murphy, 2011). Littlemore et al. (2011), for example, demonstrate this in a study involving international students (whose first language is not English) attending undergraduate lectures at a British university. A collection of lectures was recorded, transcribed and screened for metaphorically used lexis. The students' comprehension of the lecturers' discourse was subsequently assessed through interviews. It was found that $41-42 \%$ of misunderstood passages in the lectures involved metaphorical language. In fact, only $26 \%$ of the metaphorically used words in the lectures were interpreted correctly. Moreover, the students were mostly unaware of their misinterpretations and as a result did not request clarification of the metaphorical language they heard. Given these findings, Littlemore et al. (2011) called for steps that would raise the awareness of lecturers' regarding the potentially problematic nature of their abundant use of metaphor.

I wondered whether this "problem" (viz., the lack of teachers' awareness of their non-literal discourse and its potential impact on comprehension) was confined to L2 learners or might also be manifested in L1 classrooms, especially when the L1 students are not neuro-typical, as in the case of students diagnosed with Asperger Syndrome (AS). This tendency of AS-students to take figurative expressions literally has received much scrutiny in the literature on autism. Consequently, there are grounds for exploring whether AS-students in L1 classrooms may also experience interpretation problems when it comes to nonliteral expressions. Accordingly, one aim of this study is therefore to find out to what extent (if at all) mainstream high-school teachers' use of non-literal language poses obstacles for comprehension to AS-students in their classes. If the findings were to confirm that there is a problem in this regard, then this study could potentially inform professional learning initiatives that raise teachers' awareness of figurative language use with their students. 
In this study, non-literal expressions will be viewed under the umbrella of figurative language as defined by Vulchanova, Saldaña, Chahboun and Vulchanos (2015). They view figurative language as a term that covers linguistic expressions whose meanings are to be interpreted non-literally, where the recipient of the message arrives at the intended meaning rather than from what is being said literally. The spectrum of 'non-literal' language is, of course, very broad, and ranges from conventional figurative expressions such as idioms (e.g., on the back burner, to give the green light) and indirect speech act formulas (e.g., asking "would you like to give me a hand?" to express a request) to more creative uses of metaphor as well as instances of irony and/or sarcasm.

\section{Background}

Given the increasing prevalence of AS-students in mainstream classes and the request from teachers for professional development, there is a pressing need to expand autism-specific knowledge of educators and to develop interventions that improve social and academic outcomes for students with AS. In addition, while there are several studies about neuro-typical L2 learners' understanding of nonliteral expression and its relationship to academic tasks, there are few studies (Kerber \& Grunwell, 1997; Littlemore et al., 2011; \& Lazar et al., 1989) about teachers' awareness of their use of figurative language/non-literal expressions and/or use of supports to help L1 students who are not neuro-typical, as in the case of AS-students, particularly in high-school.

The overarching purpose of this exploratory study is therefore to establish whether the problem around learners' comprehension of non-literal expressions used by teachers is confined to the L 2 context or might be paralleled in L1 classrooms, especially when L1 students are not neuro-typical as in the case of students diagnosed with AS. Therefore, the primary aim of this study is to find out to what extent (if at all) AS-students in mainstream secondary education experience difficulty interpreting their teachers' intended messages when these are conveyed through non-literal utterances. The secondary aim is to explore teachers' awareness about their non-literal language use with AS-students (with L1 English) in highschool classrooms in New Zealand. An analysis of the findings may establish a 
relationship between student interpretation and teachers' awareness of their use of non-literal expressions in classroom interactions with students. The findings may either support or refute the need for awareness-raising interventions (or reflective practice) in the given teaching context.

\section{Literature Review}

Scholarly writings on autism both historically and currently have highlighted the tendency by AS-students to interpret non-literal expressions in a literal manner (Baron-Cohen, 1997; Frith, 1989). A perusal of the literature on autism seems to suggest that only a few studies (Abrahamsen \& Smith, 2000; Ezell \& Goldstein, 1992; Mercer, 2009; Whyte, Nelson \& Khan, 2013) have focused on the need for specific interventions by teachers to facilitate the understanding and pragmatic use of non-literal expressions with AS-students and language impaired students in classrooms. However, only two studies, those of Kerbel and Grunwell (1997) and Lazar et al. (1989) have focused on teachers' awareness of their use of non-literal expressions with students in L1, special education units and mainstream classrooms at primary school. In Kerbel and Grunwell's (1997) study teachers' awareness was demonstrated by the teachers' belief that they had used fewer idioms with their students than they had actually done. In the study conducted by Lazar et al. (1989) teachers' awareness was raised by demonstrating to the teachers how frequently they used multiple meaning expressions in their speech and how this could pose problems for language-impaired students. Accordingly, studies which explore teacher awareness of their use of non-literal language and the impact this may have on AS-student interpretation creates a research gap in scholarly literature on autism.

As there are more numbers of individuals with autism, which includes AS, than other clinical diagnoses such as cerebral palsy and Down syndrome in New Zealand (Autism New Zealand, n.d.), there are therefore more AS-students attending mainstream education. I suggest that this increasing trend may invite heightened awareness by teachers of the potential academic and social impacts of AS-students' tendency to interpret non-literal expressions literally. This awareness identifies a need for research in mainstream classrooms in New Zealand, and at high-school level in particular, given the dearth of research in the area of teacher 
awareness and knowledge of the extent of non-literal language use with ASstudents - and how this kind of language use potentially poses a challenge for ASstudents.

An extensive literature review addresses the aforementioned concerns and is dealt with in a three-part discussion. The first part focuses on a review of a few studies that show academic and social importance of the frequency of idiomatic expressions and the second part pays specific attention to linguistic, social and cognitive factors that potentially underpin idiom interpretation in AS-students. In the third part neurological findings that provide objective evidence for why nonliteral expressions, which include idioms, can be problematic for AS-students are addressed.

\subsection{Frequency and relevance of idiomatic expressions}

In this section studies that highlight the frequency of idiom use in educational contexts will be reviewed.

Several studies show idiomatic expressions occur frequently in oral and written contexts in classrooms (Norbury, 2004) and in daily interactions in speech communities (Bardovi-Harlig, 2012). Warren and Erman (2000) found that 52-58\% of the discourse in nineteen extracts they analysed from different texts was formulaic in nature. They made a further claim that it was impossible to dismiss the high frequency of prefabs (combinations of words, including idioms) in those texts (The London Lund Corpus of Spoken English (LLC), the Lancaster-Oslo-Bergen corpus (LOB), representing written English, and two versions of Goldilocks).

Idioms and other conventional metaphors are also very common in children's literature and in mainstream classrooms (Colston \& Kuiper, 2002). Nippold's (1991) analysis of textbooks from three different reading programmes found that by age eight children were exposed to books in which $6 \%$ of the sentences contained at least one idiom and by age thirteen $9.7 \%$ of the sentences contained at least one idiom. Lazar et al. (1989) in their study involving the frequency of multiple-meaning expressions found that $11.5 \%$ of mainstream teachers' utterances contained at least one idiom. They also noted that some teachers had been given advice to reduce or avoid using idioms with AS-students. However, given the frequency of idiom use in natural discourse and in the 
classroom, this would be a very challenging task indeed. Following Lazar et al. (1989), I would concur that the absence of idiomatic language in the classroom is unrealistic and would in fact reduce the opportunities for AS-children to build their understanding and use of idioms. Instead, it may be possible for teachers to scaffold their AS-students' comprehension of the idiomatic language they are exposed to. From this perspective, an enhanced teacher awareness of their use of figurative language would include not only an understanding of how this type of language might be challenging for their AS-students, but also an understanding of how they can help these students meet and overcome this comprehension challenge, for example, through the deliberate planning of supporting cues for interpretation.

Studies by Nippold and Martin (1989) and Nippold (1991) specifically explored idiom comprehension in neuro-typical, pre-adolescent speakers of standard English in mainstream classrooms in New Zealand. They found that idiom comprehension was associated with listening comprehension and reading skills, and idiom familiarity. Similarly, Norbury (2004) explored idiom comprehension involving neuro-typical students and like Nippold and Martin (1989) supported the association between idiom comprehension, academic attainment and literacy achievement. Taken together, the frequency of idiom-use and its importance in literacy and academic achievement therefore suggests that it would be remiss to marginalize idiom comprehension in learning. In light of this finding, an assumption may be made that by providing specific learning opportunities for ASstudents to understand idioms and other non-literal expressions, teachers will be facilitating improved academic and social outcomes for AS-students.

\subsection{Idiom interpretation and Asperger Syndrome}

In this part of the review, studies that indicate AS-students' difficulties with idioms and figurative language in general are highlighted.

Neuro-typical children learn a broad range of idioms and other figurative language in their childhood and adolescent years, however, many children with autism have significant difficulty with the interpretation and production of idioms into their adult lives (Rundblad \& Annaz, 2010; Vogindroukas \&, 2011; Whyte 2012). A study by Vogindroukas and Zikopoulou (2011) examined the idiom comprehension of AS-students and typically developing children and adults. They 
administered a decontextualized, multiple choice test of idioms to each group of participants and the AS-students interpreted figurative idioms more literally than the typically developing children and adults.

With regard to idiom familiarity, familiar idioms tend to be easier to process than unfamiliar ones by neuro-typical students (Nippold, 1991. In a review of several studies on idiom familiarity and the lexical abilities of AS-students, Norbury (2004) found that it was the lexical content of the idioms themselves that was problematic for students with AS-students and not idiom familiarity. Idiom comprehension was examined further by Norbury (2004) involving typically developing children and clinical groups (one group with features of autism and one group with language impairment). He presented the participants in all the groups with idiom tasks in isolation and in a story context. Findings from the study indicated that, while all participants had benefited from context, the groups with the features of autism and language impairment benefited less from context than the control group. He attributed this to memory for the stimulus (for example, idioms presented in the story or in isolation) and language abilities of the participants. The implication from this study is for teachers to match contexts with learner abilities in a way that supports interpretation of idioms and other figurative language. Similarly, Titone and Connine (1994) take the view that adequate interpretation is dependent upon whether or not a phrase is presented in a supportive context.

Individuals with AS often demonstrate intact language ability while at the same time experiencing a marked disruption in their ability to engage in social communication using language in pragmatically appropriate ways (Atwood, 2006). In addition, this intact language ability can be accompanied by the ability to recognize and identify written text at a much higher level when compared to their comprehension (Church, Alisanski \& Amanullah, 2000; Lanter \& Watson, 2008; O'Connor \& Klein, 2004). This higher decoding ability therefore masks the ASstudents' level of real difficulty in the area of comprehension. Bardovi-Harlig (2012) suggests that this masking could frequently mean that AS-students' teachers, parents and other communication partners assume and expect a higher level of understanding in social interactions and reading comprehension, thus challenging the socio-pragmatic competence of students with AS. 
When the linguistic, cognitive and social communication difficulties of ASstudents is considered, it is not surprising that the understanding of idioms may indeed be a real challenge for them. This is so because they need to access dimensions of familiarity and compositionality of idioms in different contexts in order to interpret them accurately. Accordingly, teaching that facilitates the understanding and use of idioms may be vital to support literacy and sociopragmatic learning outcomes for students with a diagnosis of AS.

Figurative language is also of particular importance given the pragmatic function of many phrases (for example, "would you like a hand", when offering help to someone). Norbet (2013) and Granger (1998) describe figurative language as 'linguistic resources' with pragmatics being the arena where these linguistic resources are used to communicate in different social contexts. The definitions of 'width' and 'depth' as used by (Boers and Lindstromberg (2012) will be adopted to aid the understanding of the link between idiomatic expressions and pragmatics. According to Boers and Lindstromberg (2012) width refers to the quantity of formulaic language that an individual knows but not necessarily appreciates the full pragmatic function or use of, and depth refers to how the formulas are processed to determine textual and contextual use. A further illustration where the interplay or link between the knowledge and use of formulaic language may be found, is in the relationship between 'conceptual' and 'linguistic metaphor'. In this regard, Lakoff and Johnson (1980) and Cameron (2003) define conceptual metaphor as a cognitive structure that is thought to be deeply embedded in our subconscious minds, whereas linguistic metaphor is a surface-level linguistic phenomenon. Conceptual metaphor is thought to be developed through our physical interaction with the world, through the way in which we experience our world, while linguistic metaphor with its surface level features are seen at the top (the surface). However, they suggest that the exact words used in a linguistic metaphor help when trying to make sense of it, but are reliant on both the deeper (embedded) features of conceptual metaphor and context to help with interpreting meaning.

Grounds for hypothesizing that students with AS have difficulty with processing this complex interplay between linguistic and conceptual aspects, width and depth of metaphor and, by association, non-literal expressions, include two prominent features of AS that make learning difficult both academically and 
socially, especially in the middle years (Mercer, 2009). These grounds are: Theory of Mind (Baren-Cohen, 1997) and Weak Central Coherence (Frith and Happe, 1994).

\subsubsection{Theory of Mind}

Theory of Mind (ToM) refers to considering the perspective of others, that is, forming representations of others' beliefs and perspectives and then using these representations to make sense of their behaviour and utterances, as well as inferring their mental states. In disorders like autism, the understanding of intended and contextual meanings in language may pose a challenge and such difficulties are prevalent even when individuals exhibit otherwise fluent language ability (Szatmari, Finlayson \& Bartolucci, 1990). Therefore, teachers should not assume that AS-students with fluent language ability will automatically understand the intended figurative meanings of non-literal expressions used by their teachers and peers.

In a study by Dennis, Lasenby and Lockyer (2001) students with autism displayed lower scores on a Figurative Subtest of Wiig and Secord's (1995) Test of Language Competence compared with age-matched peers. The conclusions drawn from this study indicated that students with a diagnosis of autism failed to make inferences about the mental states of others in social contexts. Similarly, Mercer (2009) also highlights social communication difficulties in AS-students such as understanding jokes and implied meanings in the language of other people.

Limited ToM ability is regarded as a core cognitive deficit in autism (Martin \& McDonald, 2004). However, Happe (1993) found that the amount of ToM individuals with autism possessed would determine the amount of figurative language they could interpret. Happe (1993) also found that individuals with autism who failed all ToM tasks could nevertheless comprehend similes, probably because the presence of $a s$ in a simile explicitly signals an analogy. However, such explicit signaling is typically absent in the case of metaphor unless the metaphoric utterance is accompanied by phrases such as 'so to speak' and 'metaphorically speaking'. She also points out that successful interpretation of figurative idioms is likely to depend on the degree of semantic transparency of those idioms. For example, skating on thin ice - where the meaning of 'a dangerous situation' can 
relatively easily be derived from a literal reading of the expression - may pose less of an interpretation challenge (at least if the student realizes the expression is not being used in its literal sense) than kick the bucket - whose figurative meaning is virtually impossible to infer from a literal reading. Unless students are already familiar with a given semantically opaque idiom, they will need to rely very heavily on contextual cues and recognition of the speaker's intent to interpret it. A study by Jolliffe and Baron-Cohen (2000) found that adults with AS are able to grasp the speaker's sarcastic and ironic intent (that is, the speaker meant something other than the literal meaning) but that they are less able than neuro-typical individuals to use contextual information to interpret the speaker`s expression. As explained above, the latter requires ToM.

\subsubsection{Weak Central Coherence}

Weak Central Coherence (WCC), proposed by Frith and Happe (1994), suggests that the difficulty that AS-individuals have with interpreting certain linguistic devices like idioms may lie in the area of 'local' versus 'global' processing, that is, there is a focus on individual detail rather than the whole meaning, or, in functional terms, a lack of big picture thinking. Frith (1989) concludes that this central system failure, WCC, is responsible for the deficits in integrating and coordinating pieces of information to form a cohesive pattern of the whole idea. A link could be made here with Wray's (2012) understanding of formulaic sequences where she views them as a stretches of words whose meanings or purposes are different from their component parts and is therefore hypothesized to be processed holistically. While this 'holistic' processing of formulaic sequences such as idioms is likely to hold true for neuro-typical language users, the global processing deficit in individuals with AS may be manifested by an inclination to break up such expressions and to rely heavily on literal interpretations of the constituent words. Jarrold, Butler, Cottington, and Jiminez (2000) have also suggested a relationship between limited ToM and WCC. In support of this, Joliffe and Baron-Cohen (2000) note that people with autism may rely on alternate and compensatory neural routes to accomplish complex linguistic tasks. They based this on observed effects of central coherence bias in tasks, both high level (requiring effortful processing) and low level (eliciting automatic processing). In addition, 
they propose that WCC may underlie ToM deficits; this implies that if the student with AS is unable to see the big picture, their ability to make valid inferences of the communicative intent of others is compromised; this therefore leads to incorrect interpretation of a non-literal expression.

While much research has still to be conducted as to the interplay between Central Coherence and Theory of Mind there appears to be little doubt that deficits in both these areas provide plausible explanations, together with additional cultural, cognitive and linguistic factors, as to why autistic students may have difficulty interpreting non-literal information.

\subsection{Neurological evidence for idiom comprehension difficulties}

Further evidence as to why non-literal language can be problematic for individuals with AS comes from research that has focused on the neurological characteristics of individuals with autism compared with neuro-typical controls. A neuro-imaging study by Wang, Lee, Sigman and Dapretto (2006) using fMRI (functional magnetic resonance imaging), neuro-typical and AS participants were presented with scenarios in which they had to determine if a character was being ironic or sincere. Information about the social event in the scenario and intonation cues were provided as well. The researchers found that the patterns of neural activity that AS-children exhibited indicated that these children were able to detect irony in others but it was done with greater effort compared to the neuro-typical group. They concluded that AS-children can make inferences about other speakers' use of irony under effortful conditions. Kana and Wordsworth (2012), in their neuro-imaging study, also found reduced responses in left hemisphere areas, particularly with a reduced response to humour.

Castelli, Frith, Happe and Frith (2002) draws our attention to studies that support the notion of dysfunction in specific neural layers for ToM (mentalizing) in autism. Mason, Williams, Kana, Minshew and Just (2008) examined the intersection of ToM processing and narrative comprehension in high functioning autism/Asperger Syndrome. This was done by comparing cortical activation during the reading of passages that required participants to make inferences based on either intentions, emotional states, or physical causality and the results indicated that there was greater right hemisphere activation or recruitment for all sentences in the 
autism group than in a matched control group. From these findings, they suggested that decreased left hemisphere capacity in autism resulted in the right hemisphere being activated or recruited for ToM processing of complex narrative material. Wang et al. (2006) suggest that this recruitment of the right hemisphere may be a compensatory mechanism to cope with the effort required to process language by individuals with autism. Findings from a study by Rapp, Mutschler and Erb (2012) involving the meta-analysis of non-literal language (metaphors, metonymy, idioms and irony) by utilizing fMRI (functional magnetic resonance imaging) with neurotypical participants indicated that while the right hemisphere plays a small, significant role for processing novel non-literal language, the predominantly left, lateralised fronto-temporal network appears crucial for processing this type of language. Therefore, it can be assumed that where studies point to right hemisphere recruitment or activation by AS- individuals for processing information we can anticipate that novel non-literal language will be problematic for individuals with this diagnosis.

Taken together, the neurological studies reviewed indicate the possibility that non-literal expressions may be cognitively challenging for AS-students. While neurological studies do not necessarily provide a direct basis for pedagogical interventions, they add to teacher understanding of potential difficulties around non-literal expressions for AS-students. Due to the heterogeneity in the population diagnosed with AS, the difficulties with processing non-literal language will vary because of individual differences in cognitive, linguistic, social abilities and experiences therefore teachers need to understand and be prepared to meet the learning needs of this diverse population.

\section{Research questions}

From the above literature review of research related to idiom interpretation and the processing of non-literal expressions more generally by individuals diagnosed with autism or Asperger Syndrome, it seems reasonable to expect ASstudents to experience some difficulty interpreting their teachers' use of non-literal language. I have also cited several studies that indicate the high prevalence of figurative idioms and metaphor in teacher talk in classrooms. Therefore, it is likely that students with AS encounter a number of idioms and other non-literal 
expressions in their daily classroom interactions. While there are more studies about the understanding of non-literal expressions by neuro-typical students learning a second language, there are relatively few studies on the understanding of non-literal expressions in mainstream education where the non-literal expressions concern the students' L1, and where student-groups include peers diagnosed with AS. Therefore, the primary purpose of the present study is to examine how well ASstudents understand their teachers when the latter resort to non-literal language. An analysis of the results would support or refute the need for awareness-raising interventions for teachers. A secondary objective is to examine teachers' awareness of their use of non-literal language with AS-students, and the strategies (if any) they use to support AS-students' understanding of those non-literal expressions. The sites where this research was conducted were nine high-school classrooms in Wellington, New Zealand. This project was given ethics approval by the Human Ethics Committee of the Victoria University of Wellington.

The following research questions guided this project:

Primary research questions:

1. How accurate (in comparison to neuro-typical students) are AS-students' interpretations of the non-literal expressions used by their teachers?

2. Do certain kinds/uses of non-literal language use by teachers pose particular challenges for comprehension?

Secondary research questions:

3. How aware are the teachers of their use of non-literal language, and what are their motives for resorting to non-literal language?

4. To what extent do teachers offer support to help their students understand the non-literal language they use, and what is the nature of that support?

\section{Methodology}

This exploratory study employed a mixed methods approach to data collection and analysis. First, episodes of teachers' non-literal language use (for example, metaphor and irony) were collected during classroom observations. This was followed by stimulated recall interviews, first with students and then their 
teachers. The students were asked to provide interpretations of their teachers' nonliteral expressions as expressed in the lessons. Students diagnosed with AS as well as neuro-typical peers from the same class performed this interpretation task. This allowed for a comparison between the responses of the AS-student and NS in order to gauge whether the AS-students faced greater challenges when it came to their teachers' non-literal language use.

\subsection{Participants}

\subsubsection{The students}

The Special Education Needs Coordinators (SENCOs) of the schools helped with the selection of student participants. They also liaised with the students' parents and teachers. Eighteen students, aged between thirteen and fifteen years, from year-levels nine, ten and eleven, participated in this study. Parents of all students, school principals, teachers and the students themselves received information letters and consent forms (see appendix). Written consent was received from the parents of all eighteen students.

All eighteen students had English as their first language. Nine of them were neuro-typical students (NS) and nine had an official diagnosis of Asperger`s Syndrome (AS) which was made by a paediatrician or clinical psychologist. Of the nine students diagnosed with AS, eight were males and one was female; seven males and two females comprised the NS-group. Gender as a criterion for participation was not specified. Each AS-student was 'matched', by teachers, to a neuro-typical peer from the same academic/learning group. Nine 'pairs' of students were thus created, each pair from a different class. None of the students had visual or hearing impairments.

The neuro-typical students were included in the study to obtain 'benchmark' data to compare with the AS-students' interpretation of non-literal language episodes. It was useful to have these 'matched controls', because, if the neurotypical students were found to misunderstand particular expressions, then the ASstudents' failure to understand these same expressions need not be attributed to their diagnosis of AS. Each pair of students (one AS and one NS) attended one of the nine lessons from which language episodes were extracted. These episodes served 
as prompts in later interviews (see further below). This was an attempt at ensuring that each pair of students experienced the same episodes in the same discursive and situational context.

\subsubsection{The teachers}

Teachers were approached via the schools' principals and heads of department. Nine teachers, all native speakers of English, volunteered to participate in this study (and gave written consent). There were six females and three male teachers. They taught either English or Social Studies, and their experience teaching in these subjects ranged from two-ten years. It was desirable for this study that classes with a high amount of teacher-class interaction were observed. The advice from teaching colleagues in high-schools was that English and Social Studies lessons would provide that rich source of data for analysis. Coincidentally, it was also through discussion with the schools that the teachers of English and Social Studies were interested in participating.

\subsection{Data collection procedures}

\subsubsection{Classroom observations and collection of expressions.}

The purpose of the classroom observations was to collect episodes of language use that could later be used as prompts in the stimulated recall interviews. These 'contextualized' expressions were used to provide a context for the interpretation of the teachers' non-literal expressions by the students. As these were retrospective interviews it was necessary to provide students' with a context in the interview task, which was to interpret their teacher's intended meaning from the non-literal prompts. Recognizing intended meaning often requires Theory of Mind (ToM), and this is what is regarded as a core cognitive deficit in autism (Martin \& McDonald, 2004). Recall that ToM refers to considering the perspective of others, that is, forming representations of others' beliefs and perspectives and then being able to use these representations to make sense of their behaviour and utterances, and to infer their mental state. The expressions were therefore collected from the classroom lessons to ensure that the students had the platform to interpret teacher expressions in context as grasping the intention of the speaker is fundamental to the 
comprehension of non-literal expressions in their contexts (Happe, 1994). This use of contextualized prompts was also guided by Nippold's study (1989) that investigated idiom comprehension in context versus isolation in neuro-typical adolescents, aged between fourteen and seventeen years. In this study it was found that accurate idiom comprehension was facilitated by contextual cues.

Each lesson was forty minutes in duration and expressions were collected mainly from the time when teachers were in interaction with the whole class. All the observed lessons followed a similar structure where the first 15-20 minutes consisted of teacher-class interaction, the second 15-20 minutes were taken up by the students' work on a given task (individually, in pairs or small groups), and the last ten minutes were used for teacher-class interaction again. All lessons had a different focus. English was taught in lessons one, two, three, four, seven and eight. In lesson one, the content was focused on reviewing essay-type questions in preparation for the exams; lesson two was a vocabulary lesson about strategies to decode words and building knowledge about word meanings; lesson three focused on planning and writing a story; lesson four was building students' knowledge about NCEA ( National Certificate of Educational Achievement- the main education assessment in secondary schools in New Zealand) marking criteria and preparing a speech for oral presentation; lesson seven was preparing students to undertake a film assessment based on the film Jurassic Park and lesson 8 was analyzing language features in song lyrics in preparation for writing a class song. Social Studies was the curriculum area taught in lessons five, six and nine. In lesson five, the students were studying the features of successful entrepreneurs; lesson six was focused on leaders and types of government in countries like Russia and lesson nine was a link between English and Social Studies where students were working on using connectives in the writing of their choice around a topic they had chosen.

Observation notes and twelve audio recordings (only teachers wore a microphone attached to a mobile phone with a built in voice recorder application) were made of teacher and student language in the lessons to obtain a collection of contextualized expressions. As teacher language was the focus of the study, observations of student use of non-literal language were noted incidentally; only one non-literal expression (see analysis of case study 2 ) involving peer-interaction during a small group discussion was identified as relevant and therefore selected for 
use in the prompts.

Non-literal expressions come in many shades and functions. Many are conventional and well-entrenched in the language (e.g., idioms, phrasal verbs, and proverbs) and AS-students may not find these hard to understand because they are so familiar with them that their established figurative meaning is accessed directly (Giora, 1997). Others are more novel and may be invented by teachers (or material writers) for didactic or pedagogic purposes, for example to explain a particular intangible phenomenon through implicit analogy, i.e., metaphor (Cameron, 2003). As mentioned in the introduction, non-literal language use also includes phenomena such as irony and sarcasm - where the intended meaning can be quite different from a literal or surface reading of the words. I thus considered as 'non-literal' those instances of language use where the intended meaning differs from 'what is in the words themselves' (if these are taken in their primary sense). Put simply, I sampled episodes of classroom language use where it seemed highly likely that an expression should not be taken literally, and this encompassed cases of metaphor as well as cases of irony.

Unlike, for example, Littlemore et al. (2011), it was not the intention in this study to identify and tally all the words used by teachers that were non-literal by applying lexicography-based procedures such as the Metaphor Identification Procedure (Pragglejaz Group, 2007), where almost any use of a word in its nonbasic sense is considered figurative. Instead, the purpose was to collect a range of instances of teachers' expressions that were clearly non-literal, to be used as prompts in the interviews. To ascertain the non-literalness of the episodes of language use that were collected from the teachers during their lessons a procedure of inter-coder agreement was used.

I collected the data and selected twelve audio-recordings and from these a total of nine were selected as they contained the highest amount of teacher-class interaction. From these nine recordings, I identified potential episodes of non-literal expressions. These were presented to two other judges, one my supervisor and the other a secondary school teacher of English. They were asked to indicate which expressions they deemed to be instances of non-literal language use. My own coding of expressions for non-literalness was guided not only by the work of Kövecses (2011) on conceptual metaphor but also by definitions in studies such as 
Swinney and Cutler (1979) and Moiron and Teidemann, (2006). Swinney and Cutler (1979) describe an idiomatic expression as one that contains two or more words whose meaning cannot be derived from the combination of its individual parts in isolation, that is, figurative meanings of multiword expressions cannot be derived through a literal analysis of each component in its lexical composition. Similarly, Moiron and Tiedemann (2006) suggest that to establish the non-literal nature of an expression, one can first assess the meaning of the expression as a whole and then assess whether this is different from combining a literal reading of its components. I also noted the importance of the wider discourse context in determining non-literalness.

Approximately $10 \%$ of the discourse from the recordings was coded for episodes of non-literal language use, representing a range of established phrases (e.g., idioms), more creative expressions, and instances of irony. The two other coders then independently considered all the selected instances and decided whether they, too, thought these were instances of non-literal language. Two meetings were held to establish the final list of expressions from each lesson to be presented to the students and teachers in the interviews. There were two expressions that did not have $100 \%$ inter-coder agreement initially but were nonetheless included in the prompts. These were "building on" what we did yesterday" and "he will freeze to death". The coding team agreed that a majority vote, that is two out of three raters' opinions would carry across the coding of teacher-expressions. Based on this, the above expressions were included in the final list.

This coding procedure yielded a total of one hundred instances of non-literal episodes of teachers' language use out of a total of one hundred and fifty-seven original expressions that would serve as 'target' prompts in the interviews, ranging from seven to sixteen per lesson observed (and consequently per interview - as the students/teachers were interviewed about the episodes they themselves had been involved in). These instances range from idiomatic expressions (for example, "you're on the right track") to more creative use of metaphor (for example, "that shows intestinal fortitude") and cases of irony/sarcasm (e.g., "I know you're dying to put up a word"). Although this does not tell us about the overall proportion of non-literal language in these teachers' student-directed discourse, it certainly illustrates that episodes where students in secondary schools are expected to 
understand their teachers' use of metaphorical language and instances of irony are not at all uncommon.

\subsubsection{Stimulated recall interviews: Students}

The students were interviewed individually two weeks after the observation of the lesson where the instances of non-literal language were collected. Interviews were scheduled for a week after the observations but due to school activities this was not possible. The interviews took place in a quiet room at the students' school. They were presented with the selected episodes (in writing as well as orally) and asked to explain the message the teacher was conveying. More specifically, I asked the students to respond to two questions:

1) What do you think your teacher meant when she/he said this sentence in the lesson?

2) What helped you to work out the meaning of what she/he said?

The students' responses were audio-recorded and transcribed, with students wearing a microphone clipped to their clothing. Students also had the option to write down their responses if they preferred, but none of them chose to do this. The interviews took between twenty and thirty minutes. Prior to the interviews the researcher offered a trial session and clarification, using a visual schedule depicting the interview process, to prepare the students for the meeting. Students were also offered the option of a support person in the interview situation, and were also informed that they could request a break at any time. However, none of the students took up these options.

\subsubsection{Stimulated recall interviews: Teachers}

Teachers were interviewed individually at their schools within two weeks of the observations. As was the case for the student interviews the teacher interviews were scheduled for a week after the observations but due to school activities this was not possible. The interviews took between twenty and thirty minutes and the teachers' responses were audio-recorded. In the interview the teachers were presented with the same episodes of non-literal language expressions as the students together with the students' responses to these expressions/prompts. This served to create an opportunity to ascertain that the messages the teachers were conveying by means of 
the expressions did or did not correspond to how the students had interpreted them. This was important given that the task in the student interviews was for the students to identify their teachers' intended meaning. The non-literal expressions and the student responses also served to elicit the teachers' reflections on their language use in their classroom. The interview with the teachers was semi-structured, and showed variability depending on individuals' reactions. The following questions were recurring ones:

1) Would you have expected a difference in the responses from the two students? (This was included to see if this influenced teachers' strategies of support.)

2) What was the focus in this activity?

3) Can you explain why you used that expression to illustrate the point?

\subsection{Data analysis}

The student responses were coded for three possibilities:

(1) There is good evidence to suggest that the student understood the teacher's intended meaning. For example, "on the right track" explained by the student as "a good sense of what we are doing".

(2) There is no compelling evidence that the student understood the intended meaning, but neither is there compelling evidence that the student misunderstood. For example, "lock it in", where no response from the student is elicited.

(3) There is clear evidence that the student misunderstood the intended meaning. For example, "narrow meaning" explained by the student as "wrong meaning".

The necessity of a distinction between response categories (2) and (3) emerged from the data (see below). It is perhaps also akin to the distinction between nonunderstanding and misunderstanding made by Bremer (1996, p.40). In cases of nonunderstanding, listeners are aware of the fact that they have not understood and may subsequently ask for clarification. In cases of misunderstanding, the listener does not realize that clarification is necessary. An inter-coder agreement procedure was used to determine which response category the students' reactions fit best. The coders were the same as those who had earlier assisted with the identification of 
non-literal expressions. In cases of disagreement, a decision was made using a majority vote, that is, two out of three raters' opinions would decide the categories into which each of the responses fell.

To compare the performance on the interpretation task by each AS-student and his/her neuro-typical peer, we tallied their correct responses for an initial, quantitative analysis. Correctness was judged according to category one (there was good evidence that the student understood the teacher's meaning) out of the three categories stated above: We then also inspected the unsuccessful/incorrect responses for a more qualitative analysis. These unsuccessful responses will be the focus in the case-by-case analyses. These analyses were meant to reveal whether certain types of episodes of non-literal language use were particularly prone to causing comprehension problems for AS-students and also to find out more about the AS-students' strategies for overcoming such problems.

\section{Results and Discussion}

The data from the student interviews will be reported on first, and in more detail than the teachers' responses, as the student data addressed the primary aim of the study. The findings from the teachers' interviews will be discussed following the report on the student data.

\subsection{The students' comprehension of their teachers' expressions}

\subsubsection{General results}

Scholarly readings of the literature on autism has highlighted the tendency of AS-students to take figurative expressions literally, andso there are grounds for hypothesizing that students with AS in L1 classrooms are likely to experience interpretation problems when it comes to non-literal expressions. The primary aim of the proposed study was therefore to find out to what extent (if at all) mainstream high-school teachers' use of non-literal language poses obstacles for comprehension to AS-students in their classes. Table 1 compares the AS-students' success rate (category 1- clear cases of understanding) at the interpretation task as compared to their matched classmates. 
Table 1. Comparison of AS and NS interpretations to target prompts

\begin{tabular}{|llllllllll|}
\hline Lesson & $\mathbf{1}$ & $\mathbf{2}$ & $\mathbf{3}$ & $\mathbf{4}$ & $\mathbf{5}$ & $\mathbf{6}$ & $\mathbf{7}$ & $\mathbf{8}$ & $\mathbf{9}$ \\
\hline $\begin{array}{l}\text { Total Target } \\
\text { (non-literal) } \\
\text { Expressions }\end{array}$ & 16 & 7 & 9 & 7 & 14 & 12 & 10 & 13 & 10 \\
\hline AS & & & & & & & & & \\
\hline NS & 11 & 5 & 7 & 4 & 10 & 13 & 9 & 13 & 8 \\
\hline
\end{tabular}

Table 1 shows the total number of non-literal expressions (prompts) per lesson and the difference between AS and NS responses to them. Eight of the nine ASstudents' scores were lower than their neuro-typical peers and one AS-student obtained the same score as his neuro-typical peer. These data are consistent with the expectation that the AS-students would find it harder to interpret the intended meaning behind non-literal language use. Despite the small sample size, a Wilcoxon Signed Rank's test even indicates that the difference with the NS' scores is significant ( $W=-36 ; p=.01)$. At the same time, it needs to be said that, where there was a difference in the accuracy of AS-students' interpretations compared to their neuro-typical peers, this was usually a relatively small difference.

Table 2 shows a breakdown of the number of misinterpretations of the non-literal expressions (prompts) judged according to (categories 2 and 3) for each AS and NS. The misinterpretations will be addressed in more detail in the case-by-case analyses which will be discussed next.

Table 2. Numbers of responses by AS and NS that did not furnish evidence of successful comprehension

\begin{tabular}{llllllllll}
\hline Case & $\mathbf{1}$ & $\mathbf{2}$ & $\mathbf{3}$ & $\mathbf{4}$ & $\mathbf{5}$ & $\mathbf{6}$ & $\mathbf{7}$ & $\mathbf{8}$ & $\mathbf{9}$ \\
\hline $\begin{array}{l}\text { Category 2 } \\
\text { No clear case of } \\
\text { understanding or } \\
\text { misunderstanding }\end{array}$ & $1(\mathrm{AS})$ & & $1(\mathrm{AS})$ & $3(\mathrm{AS})$ & $1(\mathrm{AS})$ & $1(\mathrm{AS})$ & $1(\mathrm{AS})$ & 0 & $2(\mathrm{AS})$ \\
& & & $1(\mathrm{NS})$ & & & & & & \\
\hline $\begin{array}{l}\text { Category 3 } \\
\begin{array}{l}\text { Clear case of } \\
\text { misunderstanding }\end{array}\end{array}$ & $2(\mathrm{AS})$ & $2(\mathrm{AS})$ & $1(\mathrm{AS})$ & & $3(\mathrm{AS})$ & $1(\mathrm{AS})$ & 0 & 0 & 0 \\
& $1(\mathrm{NS})$ & & & & & & & \\
\end{tabular}




\subsubsection{Case-by-case analyses}

In what follows, I report in more detail on what responses were given to particular prompts and how some of the AS-students' responses differed from their neurotypical peers.

I shall do this on a 'case by case' basis by looking at each pair of students (and thus at each set of prompts per lesson) in turn. These more detailed reports will also incorporate discussion of implications that could be drawn from the findings. The expressions which the students were asked to interpret are highlighted in bold.

\section{Case 1}

The AS-student demonstrated four inaccuracies in the interpretation of the nonliteral prompts. This compares to only one inaccurate response by the NS.

Focus will now turn to the expressions where the literal readings were incongruent with the intended figurative meanings, especially when irony and sarcasm were the intentions of the speaker. The three expressions used by the teacher illustrating the use of sarcasm and irony was analysed. In the first expression, the teacher was talking to a student who gave her an excuse for not doing his homework to which she replied: “At least the dog didn't eat your homework". When asked what the teacher meant, the AS-student responded: "I didn't get that. It would have been a joke, so it would have taken me a while to work that one out. I have never heard of that until now." The NS responded with a smile and said: "She's probably making a joke." When I asked both students what helped them work out the meaning, both students replied that it was because their teacher laughed. The NS also added that "(the student) wouldn't have given that as an excuse for not doing his homework, so it must have been a joke." While the ASstudent's response demonstrated a clear case of not being able to express the sarcasm as compared to the NS, he did demonstrate metacognitive awareness /metarepresentation, the ability that something represents something else (Whyte, 2012). Here, the AS-student demonstrated awareness that the teacher's utterance was funny in some way and therefore was likely to have made a joke. This was demonstrated by his use of the word "joke". However, working out why it was funny was apparently harder for him to understand or explain. His response of "I have never heard of it until now" clearly indicated that he was not familiar with the 
expression. The unfamiliarity was an additional factor (obstacle) that appeared to prevent him from interpreting this expression.

In the case of the second expression, the teacher was trying to encourage the students who were non-responsive in the lesson by saying to this to them:

"Come on, I know you are dying to put up a word". The AS-student reported that the teacher meant "that we couldn't wait to put up a word", and the NS responded with, "probably being sarcastic by saying we were dying to do it but really we were all tired." When compared with the NS, the AS-student demonstrated that he did not understand the sarcastic intent, but he appeared to have been familiar with the words of the expression. The latter was also illustrated in the interview where, when asked how they worked out the meaning of what their teacher meant, the AS-student said it was the words, "dying to put up a word". Accordingly, he interpreted this as "we couldn't wait". This was the opposite of what the teacher intended to convey. The NS said it was "the way the teacher said it" that helped him recognize the sarcasm, thereby demonstrating his understanding and use of prosodic cues to interpret the teacher's intended meaning. This also demonstrated ToM as he was able to interpret the perspective of the teacher as compared with his AS-peer who was unable to process her intent.

The third expression the teacher used was: "Okay who will come up first, who's got their feet on fire; who's ready to dance their way to the board?" In this context, the teacher was trying to liven up the lesson. At the time of speaking she simultaneously clicked her fingers and quickened her speaking rate. The irony seems to have been missed by the AS- student, whose response was, "the teacher wanted to see who wanted to come up first." This seems to point to a ToM deficit as he was unable to interpret the ironic intention of the teacher. It may have been the case that he had difficulty with processing the number of elements in the expression, and therefore had difficulty explaining what he was thinking. Minshew and Goldstein (1998) showed this in their description of the cognitive profile of individuals with autism spectrum disorder as being a disorder of complex information processing across cognitive domains. They define complexity in terms of the number of elements contained in the stimulus material that has to be processed in order to perform the task, in this case the number of steps in the teacher's instructions or the number of words contained in each expression that the 
student had to process to accurately interpret the speaker's intended meaning. It may also have pointed to Weak Central Coherence (WCC) proposed Frith and Happe (1998) concludes that this central system failure, WCC, is responsible for the deficits in integrating and coordinating the bits of information to form the whole. This may have been reflected by the AS- student's difficulty in integrating all sources of information to arrive at the teacher's intention of the teacher's meaning as demonstrated by the NS's response, which was, "she was trying to be funny, to say come on guys, but we were all tired."

The AS-student also demonstrated a misunderstanding of the teacher's expression "Connect the essay question to this short story". The teacher said this while writing this sentence on the whiteboard; she put the essay question above the short story title and connected them with an arrow; the essay question was above the short story title on the board. The AS-student interpreted this instruction as "put the essay title below the title." The NS, on the other hand, interpreted the instruction correctly as intended by the teacher. He made the connection between the essay question and the short story that the class had been analyzing as indicated by his response that the teacher meant "linking the essay question to the short story". When the AS-student was asked what helped him to understand what his teacher meant he did not provide a response. This could have meant either that he was unable to explain how he derived that meaning or that he obtained the cue from the teacher's visual where she put the title of the essay question above the title of the short story on the board, and connected them with an arrow. There is therefore the possibility that he focused on the visual and missed the meaning behind the teacher's oral instruction, that is, the student interpreted the expression from the teacher`s use of the visual in a literal manner. An important pedagogical implication arises for teachers from this example. This is, when using visuals to enhance the clarity of verbal instructions, teachers need to be aware of the possibility of ambiguity or lack of congruency between the two stimuli for students. For example, Samuels (1970) discussed the focal attention hypothesis, suggesting that when pictures and printed words are presented together, (young) readers will tend to attend to the pictures rather than the words.

One episode caused confusion for both the AS-student and NS. This happened when the teacher said, "Right let's make up a game; I will make it up 
and you will be the guinea pigs", where the analogy of the guinea pig (in a test situation) used by the teacher was not understood by either of the students.

However, the students did seem to understand that it was an instruction where they were the "doers" and the teacher would instruct/control the game. When I asked both the students what helped them to understand the meaning of the expression "you will be the guinea pigs", the AS-student said it was the teacher's words, "I will make it up", and "so it means we will play it." The NS responded with "I think guinea pigs means like the workers, the students." It seemed that this was an unfamiliar expression for both the students.

Summing up, findings from case 1 indicate that the AS-student demonstrated clear misunderstanding of two utterances: one conveying irony or sarcasm and one where the stimulus contained multiple elements to process. In another expression that contained sarcasm he demonstrated metacognitive awareness by recognizing that it may have been funny in some way, but he acknowledged not understanding in what way it was funny. This was an example of non-understanding rather than misunderstanding. Initially, it was difficult to make a clear distinction between a misunderstanding and a non-understanding. However, the raters deemed this response to be a non-understanding (Bremer, 1996, p.40).

There was only one expression (guinea pigs) which also the NS failed to understand, due to lack of familiarity with the expression. In this case, it was judged to be a category 2 , that is, no clear evidence of understanding or misunderstanding.

Case 2

In lesson two there were two non-literal expressions analysed. The first one was when the AS-student and NS both misinterpreted the non-literal expression: "that is a very narrow meaning." The context was the teacher reviewing the word choices that students had selected in a vocabulary task. The AS-student thought it meant "hard" and the NS thought it meant "the wrong meaning". It seems that neither student understood narrow in this phrase. It would seem that the interpretation of narrow meaning is not easily derived from the combination of its constituent words, if one does not already know it.

In one conversation where the AS-student was participating in a discussion with two other students about computer software, one student in the group got into 
an argument with them and responded to their comments with "Sorry, Mr. Genius,

I didn't know." In the interview the AS-student was unable to explain that his peer was being sarcastic; it seemed that he did not recognize the sarcasm at all. This was demonstrated by his response, "he was sorry". He also reported that the word "sorry" helped him understand the meaning. This indicated a clear case of misunderstanding. In comparison, the NS demonstrated his understanding of the sarcasm with this response: "he was being smart. It was sarcasm, the way he said it."

Findings in case 2 indicated that the NS student showed one clear misunderstanding and the AS-student demonstrated two.

\section{Case 3}

In lesson three, two expressions were analysed. The first expression, "If the cat is out in the cold, he might freeze to death", posed similar difficulties for both students. The teacher's intended meaning was that the cat could die if left outside, in the cold. The AS-student's response that "he was cold" seems to indicate that he either misunderstood or could not explain the teacher's meaning. It is also possible that he did not process the whole expression which led to him misunderstanding it. This could be the same situation for the NS; he appears to have focused on the word freeze, as shown by the response, "stand in one position forever" which is indeed close to one meaning of the verb freeze. When asked what helped them to work out the meaning the AS-student said that it was, "that the cat was cold" and the NS's response was that it was the word "freeze." It appears that part of the instruction was processed and therefore only part of the expression was interpreted; the causal link between being out in the cold and freezing to death was not clear to either student. Therefore, there is no clear evidence that the AS- student had any greater difficulty interpreting or explaining this expression.

In the case of the teacher's expression, "How are we going to wrap this all up", there was evidence of inaccurate interpretation by the AS-student compared to his neuro-typical peer. The teacher used this expression when she was instructing the students to think about how they would conclude the story she had developed with them; this was an example for the students when they developed their own stories. The NS interpreted this expression accurately by responding with "finish it 
up", while the AS-student responded with "everything goes bad". In the interview, where he was asked what helped him to give the answer he replied, "the words wrap up, you put it away". His response of everything going bad may be indicative of him thinking about his story where it ends with "everything goes bad" for the characters. This alludes to a deficit in ToM where the student may have focused on his own action or thought, and not on the teacher's intent where she was asking a general question to the class about how the story was going to conclude. It could also have been the use of the question "how are we going to wrap this all up?", and he literally answered it with "everything goes bad" rather than explaining the expression. While this is a case of inaccuracy in the way the AS-student interpreted the expression, it is not crystal clear that he did not understand the teacher at all.

A summary of the findings here, indicates one clear case of misunderstanding by the AS-student and one response that indicated that there was no clear evidence of misunderstanding or understanding by either student.

\section{Case 4}

Three expressions that were identified as being potentially problematic for the ASstudent as compared with the NS were analysed.

In the first expression, "If you are still agonizing about what to write, you can think about it today but lock it in by tomorrow", the teacher was instructing the students to finalize their topics by the next day. When asked what the teacher meant, the ASstudent provided no response at all. This lack of response may indicate she did not understand the expression. On the other hand, it may also have been due to confusion about the task or to difficulty explaining the meaning of the expression.

There are several levels to process in this instruction which may have been difficult for the student to work through. It may be that she chose to provide no response as a path of least effort knowing that the interviewer was waiting for an answer. In addition, in the context of this classroom the teacher was talking to the class group and not specifically looking at the AS-student, and so it may be that the student thought the teacher was using the pronoun "you" to another student where the teacher was physically positioned, and not to herself or the class group as a whole. This may also be an instance where a ToM deficit could be a plausible explanation for no response from the AS-student; the student did not make an 
inference from the teacher's expression that she (the teacher) was talking to the whole group which included her, not just the student the teacher was standing next to, or looking at.

The number of possible explanations for why the AS-student did not respond made it difficult to conclude that it was a clear case of misunderstanding. As the student did not produce a response, it was not necessary to ask how the meaning was obtained. Instead, I asked which word or words did she not understand, and she replied, "I'm not sure." In this instance there is only evidence to suggest that she had some difficulty producing a response but not that she misunderstood it as compared with the NS whose interpretation of the teacher's message which was, "She meant if you are still confused, think about it today but it has to be in tomorrow". When the NS student was asked what helped her to interpret the teacher's meaning she said, "It was the words lock in. She wants you to decide by tomorrow." This was the meaning intended by the teacher and was therefore interpreted accurately.

In the second expression, "you need to have a strong topic", the teacher meant choose a topic that "has a lot of information (about it)" and one that the students themselves were interested in. However, we could suggest that the word strong is ambiguous and therefore it is not surprising that the AS-student did not provide a response that matched the teacher's intended meaning. However, the difference in the two responses indicated that the NS understood the teacher's message as it was intended ("a topic that you are passionate about") when compared with the response of the AS-student ("talk about something that is explained well. Everyone can understand what your argument is about"). The NS student interpreted the words "strong topic" to mean passionate which seemed to be more in line with the teacher's intended meaning of a topic that the students were themselves interested in. The AS-student, on the other hand, interpreted the phrase "strong topic" as a topic that is written well and understood by others. This is not an incorrect interpretation if we take "strong" to be ambiguous, just one that was not akin to the intended meaning expressed by the teacher. In the interview, when asked what word helped with understanding the meaning, both students said it was the word string "strong topic". The AS-student was therefore not incorrect in her interpretation of the expression if we consider the ambiguity in the word strong; she 
seemed to have the correct end goal in sight, that is, to have a strong argument that could be understood by all. Therefore, while there was a difference between the NS and AS-students' responses to the teacher's interpretation, there was no compelling evidence that the AS-student clearly misunderstood the teacher.

The third expression used by the teacher in this lesson was "Get ready, chop-chop”. The teacher's intended meaning was for the students' to hurry up. When asked what helped them interpret the meaning of "chop-chop" the ASstudent replied it was "get ready" whereas the NS student said it was "chop-chop". It would seem that the AS-student focused on "get ready" as she interpreted the meaning to be, "She means to look at her and stuff and stop what we are doing", while the NS interpreted the expression to mean "hurry up"; this was the meaning intended by the teacher. On the surface, this demonstrates a case of misunderstanding by the AS-student. However, on closer examination, it seems she knew the teacher's intention which was to get ready; she perhaps could not paraphrase in her own words what "chop-chop" actually meant, whereas it was clear that the NS understood and explained it in line with the teacher's intention; "get ready" was possibly more familiar than "chop-chop" to the AS-student. Besides, chop-chop is also semantically incongruent with its figurative meaning, and so this may have been potentially problematic for the AS-student. It is possible that when she heard "get ready", "chop-chop" was redundant or even that she did not hear it as she was busy getting ready after having processed the first part of the utterance ("get ready"). However, there was no clear indication that she did not understand the teacher's intended message.

Summing up findings in case 4, the NS interpreted all the teacher's expressions more accurately than the AS-student and as intended by the teacher. While the AS-student demonstrated inaccurate interpretations to her teacher's expressions it was not conclusive as to whether these were due to comprehension difficulties alone. In other words, there was no clear evidence of misunderstanding.

\section{Case 5}

Four non-literal expressions were analysed from this lesson.

In this first expression, "In the case of Richard Branson`s rocket, that crashed, and they are still picking up the pieces, metaphorically speaking”, the AS- 
student's response was “Er, I think it didn't actually crash. I know that from the word metaphor". This demonstrates metacognitive awareness evidenced by him mentioning that the rocket did not really crash and that he knew this from the word metaphor. This shows that the AS-student had some difficulty with explaining the metaphor as opposed to not understanding the teacher's message at all. The NS interpreted and explained the expression more accurately: "The business hadn't gone too well and they are still trying to put it together, metaphorically speaking; it is a failed rocket".

In the second expression that was used by the teacher, "He was a single face in front of the business with a strong team beside him", the AS-student reported that the words "single face" helped him work out the meaning of the expression to be "he did a lot of the work by himself but he also got a team to help". He appeared to extrapolate the meaning "did a lot of the work by himself" from "single face in front of the business". While this was not wholly inaccurate in relation to the teacher's intended meaning if we consider the entire utterance, it does point to a literal interpretation, and therefore a misunderstanding. Perhaps he did not know the word representative, which may have impacted his ability to understand the expression. Nevertheless, there is evidence to suggest that he interpreted the expression literally. The NS, on the other hand, expressed the meaning more accurately as, "he was the representative of the business. He was backed up by a team who certainly helped him a lot. He was the first face people would see of the business". This is a clear case of accurate interpretation by the NS and a clear case of misunderstanding by the AS-student.

In this third expression, 'See, he is dropping names" the teaching was referring the students to a video clip of an entrepreneur who was mentioning other high profile business people during an interview. The teacher's intended meaning was that the entrepreneur was giving importance and support to his (the entrepreneur's) idea by mentioning familiar, high profile business people that he knew. The AS-student's interpretation was "He is meeting other people and collecting names that could help him or he could work with." The NS's response was "He's giving other people's names to back up what he is saying". This illustrates that the NS has demonstrated an understanding of the teacher's intended meaning more accurately as compared with the AS-student. 
The AS-student reported that the word "dropping" helped him obtain the meaning of "dropping names", while the NS said it was "name dropping"; she had switched the words around, demonstrating that she accessed the idiomatic meaning automatically to obtain the figurative/implied meaning. As the teacher's expression of dropping names is not congruent with its figurative meaning this possibly made it more difficult for the AS-student to interpret. When comparing the two students' responses, there is clear evidence that the AS-student has misunderstood the meaning of this expression as compared with the NS who interpreted it accurately.

In the fourth expression, "good entrepreneurs cross the chasm between thinking and doing" the teacher's intended meaning was that entrepreneurs take ideas and do something with them; they do not just think about them. When interviewed, the AS-student reported that he used the word cross in "cross the chasm" to obtain the meaning of "getting over something". However, he did not demonstrate that he understood what the teacher meant. It may be that he was not able to explain it, but it does point to a misunderstanding as well. This is compared with the NS's response which was, "It means that entrepreneurs, they just don't think about doing something they take the idea and cross the boundary and do something about it".

Findings from case 5 indicated that the AS-student demonstrated misunderstanding of expressions as well as difficulty with paraphrasing. He also demonstrated metacognitive awareness in his interpretation of two expressions but could not explain them and interpreted one expression in a similar way to his neurotypical peer.

\section{Case 6}

Two expressions from lesson 6 were analysed. The first one is, "sort it out", where the teacher was telling the student off for not bringing his book to class. Her intent was that he needs to fix up the problem and come prepared next time. The ASstudent interpreted this to mean "just get a different book". He appeared to be proposing a solution to the issue expressed by the teacher. When the teacher was interviewed she reported that she sometimes proposes that students use a different book if they do not have the appropriate book with them, as a way to sort it out/fix the problem. So, when we consider the AS-student's interpretation it might have 
been the case that the AS-student used past contextual cues to ascertain the meaning of the expression. Of interest too, was that the teacher's expression may have presented as being ambiguous, combining a solution from past contexts and a warning for the future. Also, as noted in the observation notes, she did use a tone of voice and displayed a facial expression that indicated that she was not happy, which the student appears not to have noticed.

This expression generated some debate amongst the raters as it was not crystal clear as to whether the AS-student did clearly misunderstand the teacher`s expression. Two out of three raters decided that it was not a clear case of misunderstanding or understanding therefore the expression was coded under category 2.

In contrast to the AS-student, the neuro-typical student interpreted the teacher's expression to mean "come prepared and organized next time". This was an accurate interpretation of the teacher`s intent.

With the next expression, "I get tongue-tied on this word totalitarianism", the AS-student responded with "she is sick of repeating the word" compared with "she couldn't get the word out" which was expressed by the NS. It is clear that the AS-student's response is a misunderstanding compared to that of the NS who has expressed the teacher's intended message accurately. When the students were asked what helped them obtain the meaning of what their teacher said, the AS-student replied that it was because he remembered her saying this in the class, while the NS replied that it was the words "tongue-tied".

Findings in this case indicated that the AS-student's responses showed one case of clear misunderstanding and one where there was no clear evidence of either understanding or misunderstanding.

\section{Case 7}

Only one expression was sampled in this lesson.

In the course of the lesson, the teacher was asked why he was wearing a microphone during the observation and he replied "I am part of an observation because only good teachers get observed and bad teachers skew the data." The teacher had a smile on his face when he said this. The AS-student responded with “It's a joke, I think, I don't know." It's a little confusing what he meant”. The NS 
responded with "I think his attitude was he was joking about it". The utterance was seemingly interpreted by the AS-student and the NS in a similar way but the ASstudent seemed more unsure. However, both students were not able to explain the meaning of what their teacher said, even though they both picked up on the possibility of it being a joke. When asked what helped them work out the meaning, both the AS-student and NS said it was the teacher smiling.

Findings indicated that neither student demonstrated a clear misunderstanding in their responses, but as the AS-student indicated that he was less sure this was coded under no compelling evidence of understanding or misunderstanding. When the raters reflected on this, the NS students' response could have been coded here as well.

\section{Case 8}

No differences were found in the student responses. Both students interpreted the teacher's expressions accurately.

\section{Case 9}

In the following two expressions it was difficult to determine conclusively whether the AS-student did not understand, could not explain or did not remember the context. However, a comparison with the NS's responses indicated that they were different, with the NS interpreting the teacher's expressions more accurately.

In the first expression, "hold it", the AS-student's response was that he was "Not sure, maybe everyone was yelling". Interestingly, I observed that the students were noisy and yelling while the teacher was talking. So, whether this was a case of misunderstanding or not being able to explain was hard to say. It could also be that when he (the AS-student) said "not sure", he was meaning that he was unsure of the context as this was a retrospective interview, or unsure of the meaning of the expression, or unsure of what he needed to tell me. Nevertheless, he was unable to explain what the teacher meant by "hold it", which was for the students to stop what they were doing and listen to him (the teacher). The neuro-typical student's response on the other hand, was "Listen up", which was an accurate interpretation of the teacher's expression.

In the second expression, when the students were asked what their teacher 
meant by the expression "fill you with fear, then you will do your homework", the AS- student responded with an echoic-type response "fill you with fear" compared to the NS's response of "scare us into doing work". The AS- student may have been unable to explain the meaning or he may not have understood it at all. Also, he may have assumed that the interviewer already knew what his teacher meant. This was demonstrated in the interview when he was asked what helped him to understand the meaning; the student nodded and said "fill you with fear." Another possibility is that the expression may have been unfamiliar to him. This analysis highlighted a number of possible explanations as to why the AS-student did not interpret the teacher's expressions according to the intended meaning by the teacher. However, it did not point to clear evidence of understanding or misunderstanding.

The findings from these snapshots indicated that the AS-students' success at interpreting their teachers' non-literal utterances was variable, but overall they tended to be less successful at the interpretation task than their neuro-typical peers. Some of their responses showed clear signs that they had misunderstood the teacher's intended meaning while other responses were harder to assess as they furnished neither clear evidence of correct or incorrect interpretation. In such cases, it did not rule out the possibility that the AS-students understood the teacher's intention as well as their neuro-typical peers; that is, they simply did not clarify or express this understanding well enough in their responses provided in the interview.

\subsubsection{Expressions that posed particular problems for students}

A mixture of non-literal and other types of expressions were analysed to determine the types of expressions that may pose particular challenges for the students, particularly the AS-students. While most non-literal expressions were interpreted fairly accurately by NS and AS-students, the AS-students did appear to interpret non-literal expressions less accurately overall. Findings from the analysis indicated that the AS-students experienced difficulty, in particular, with utterances that contained puns, irony and sarcasm but they displayed metacognitive strategy use that helped them to detect or recognise their teachers' use of irony, sarcasm, (creative) metaphor and pun. However, this alone did not always lead to a precise understanding of the teachers' intended message. At the same time, it needs to be borne in mind that the AS-students' 'true' understanding may at times have been 
concealed due to a difficulty with expressing that understanding. Unfamiliar idioms and words were also found to underpin unsuccessful interpretations of teacher language, but this held true for both the AS and neuro-typical students.

\subsection{The teachers' reactions}

\subsubsection{Teachers' expectations of student performance}

Eight out of the nine teachers expected to see a difference in the responses between NS and AS-students. These teachers also reported that they expected the ASstudents to perform poorly compared to their neuro-typical peers. The reasons they gave for this included expectations that AS-students would have difficulty with interpreting irony and humour and would "take time to process the information". Despite one teacher expressing "I know that people with Asperger Syndrome have trouble with humour", there was no apparent use of strategies to support this knowledge in the actual discussion-time in the classroom. One teacher reported "I use these expressions with all my students, so I know that some will get it and some won't". This was demonstrated in most of the lessons where the difference in the scores between AS-students and NS was attributed to the AS-student having difficulty explaining the expressions that contained irony and sarcasm. The same teacher reported that the AS-student would have difficulty expressing himself, "even if he understood the expression". This was confirmed in the analysis of the responses (see case 1). One teacher commented: “Oh, they are closer than I thought" (referring to the scores of both the AS-student and NS), which she apparently was not expecting (see case 2). One teacher did expect the AS-student and the NS to have a similar understanding, as the AS-student was "keeping up with the class". This was indeed demonstrated by the pair of students that obtained the same score in lesson eight. Overall, none of the teachers reported the need to modify their strategies to match their expectations of student performance, especially with regard to the AS-students. This would be useful to follow-up in a study with a focus on teacher cognition, primarily teacher awareness of strategies used in their classroom practice with AS-students. 


\subsubsection{Teacher motives for non-literal language use}

Motives for why teachers' used certain expressions was explored in interviews with participant teachers. These were examined for commonalities and didactic themes. Overall findings indicated that when the teachers were asked why they used non-literal expressions, one teacher did not know why, and three reported that they were modelling and teaching new vocabulary in their lessons (for example they used expressions like "that's great intestinal fortitude, it takes guts" and "you will be the guinea pigs"). One of the three teachers who reported that she was modelling language also expressed that these expressions were a way to incorporate humour ("who's got their feet on fire, who's ready to dance their way to the board" when the students were non-responsive); two teachers found it an efficient way to communicate by avoiding long explanations in order to grab the students' attention ( "cut it out" and "chop chop"); two teachers reported that it was their personal communication style (for example, "using too many colloquialisms" and using expressions like "sweet", "no worries", "spot on"), and one teacher expressed that they were topic-specific expressions and analogies that she could use repeatedly in a unit of work to capture what she meant. An example of this was in the lesson on writing a story where the expressions used included "building tension", "cliffhanger" and the rollercoaster model to show twists and turns of the story writing process. This captures what Cameron (2003) highlights as the didactic of pedagogic use of metaphor (as an implicit analogy) to explain processes.

Interestingly, the teachers in lessons one, five and eight who gave reasons for modelling these expressions in their lessons were the ones who used the most non-literal expressions, but none of them were aware of the extent to which they used them. However, the extent to which to which teachers were aware of their use of non-literal expressions was not the primary focus of this study.

In summary, teachers' motives for using non-literal expressions were identified to be modelling, humour, efficiency of use, teaching new vocabulary, personal teaching and communication style and genre-specific use to support a particular process (the rollercoaster example). Modelling and building students' vocabulary knowledge were highlighted by most of the teachers as motives for using non-literal expressions, followed by efficiency - use of analogies rather than long explanations, and personal teaching/communication style. Only one teacher 
reported the planned use of non-literal expressions; that is, there was evidence of predominantly incidental use by most of the teachers.

\subsubsection{Teachers' Strategies of Support}

Data from the teachers and student interviews together with classroom observations were used to examine teachers' use of strategies to support students' interpretation of the expressions. One teacher used non-literal expressions to signal task changes and topic changes (for example, "now, we are going to get into some rhyme", "let's check-in with each other in five minutes; get through the exercise then we are going to look through the songs"). However, the teacher did not identify this as a deliberate didactic strategy as a support to assist student interpretation of non-literal expressions. This support of signaling task and topic changes appeared to be effective in maintaining students' attention and engagement. Two teachers were observed to use additional/clarifying language alongside non-literal expressions, for example, "that's great intestinal fortitude, it takes guts" (see case 6) and "they're still picking up the pieces, metaphorically speaking" (see case 5), which supported the AS-student's understanding, in both instances; this was evidenced in the responses the students provided in the interview situation. In another instance (see case 1), the teacher used the expression: "I will make it up and you will be the guinea pigs" while she was making up a game for the students that she wanted to try out with them. In this expression she was using the medical science analogy of testing guinea pigs in experiments in a laboratory. The teacher assumed that the students would understand this and therefore offered no clarification. As discussed in the case 1 findings, neither the AS-student nor the NS interpreted this expression correctly, as it was unfamiliar to them. So, if the teacher's motive was to enhance vocabulary and figurative language understanding through incidental modelling, the chances were very slim that the students would have understood this non-literal expression from one encounter only. Support for this notion comes from a study by Webb, Newton and Chang (2013) on incidental learning of 'collocations' (most of which were actually idioms) in L2 vocabulary learning where the adult students demonstrated slow uptake of idiom learning from incidental exposure only. The study found that repeated encounters were necessary for faster uptake and memorability. The implication from these findings for teachers 
in L2 settings is that deliberate instruction with repeated encounters is necessary for students to learn and remember idioms. I suggest that these strategies could be potentially useful to support AS-students understanding of figurative language.

A video of a real-life rollercoaster ride was used by one teacher to show the students how the rollercoaster ride was like writing their stories. She explained that she did this to clarify the story-writing process with a "real-life video" as some of the students had never been on a rollercoaster ride. Both the AS-student and the NS in this lesson reported that this helped them understand the parts of the story they had to write, for example, the "high point" was interpreted by the AS-student as "the exciting part, where the main action is happening", and the NS interpreted the high point as "where the good things are happening".

All the teachers used visual strategies in their lessons (digital technology, writing on the whiteboard, video clips) alongside their discussions and instructions to support their students' understanding and engagement. However, there was one instance where the clarification, drawing of the instruction on the whiteboard, led to the AS-student interpreting the expression incorrectly (see case 1 - "connect the essay to the short story"). The student followed the visual and as the visual was not congruent with the teacher's verbal expression, this led to him misinterpreting it. So, there was a disconnect between the oral instruction and the visual support. This highlights an important pedagogical implication, that of congruency between visual and oral cues when working with students who have processing difficulties and who have a tendency to interpret information literally.

Interestingly, none of the teachers offered any paraphrasing of expressions, particularly those containing humour, irony or sarcasm nor did they offer any opportunities for the students to clarify the intentions behind the expressions the teachers used. This finding included the teachers who said they knew that students with AS have difficulty with interpreting expressions that contained irony or sarcasm. However, it is possible that the teachers knew their students' abilities and perhaps engaged in clarifying meanings of these expressions at other times, but not on the days of the observations. It may also be the case that by the time AS-students arrive at high school they are assumed to have developed strategies to interpret most of these expressions and therefore teachers do not see the need to offer clarifications when they use certain expressions. 
Another finding was that familiar expressions/ classroom language used by the teachers (such as "I will get through all of you today"; "spot on" and "you're on the right track") were understood by both groups of students in all cases in this study. However, and expectedly, there were expressions and word meanings that were misunderstood and unfamiliar to both groups of students such as "narrow meaning", "freeze to death" and "you be the guinea pigs" (see cases 1, 2 and 3). Evidence for supporting the familiarity position is highlighted by studies reviewed by Norbury (2004) which showed that familiarity of idioms is not problematic for AS-students. Considering that familiar idioms are easier to process than unfamiliar ones in neuro-typical students (Nippold, 1991), the findings in this study showed that this was the case for the AS-students as well. One possible explanation for why familiar expressions are easier to process may be that many non-literal expressions are conventional and well-entrenched in the language (e.g., idioms, phrasal verbs, and proverbs) and AS-students may not find these hard to understand because they are so familiar with them that their established figurative meaning is accessed directly (cf. Giora's (1997) Graded Salience hypothesis). Perhaps this also suggests that knowledge and familiarity of specific idiomatic phrases builds up gradually over time which supports more accurate interpretation of them.

With regard to contextual cues, the AS-students in this study did not always pick up the meaning from the context when they were presented with unfamiliar expressions or vocabulary (where guessing the meaning from the context was an option). In parallel findings within an L2 context, Boers, Eyckmans and Stengers (2007) suggest that neuro-typical learners in L2 usually fail to comprehend unfamiliar idioms even when these are embedded in contexts that are rich in contextual cues. It would seem that contextual cues alone are not sufficient to support interpretations of unfamiliar non-literal expressions for L2 students and by implication, possibly, with AS-students as well. Relatedly, in their study involving adults, Joliffe and Baron Cohen (2000) found that AS-adults had more difficulty than neuro-typical individuals when interpreting a speaker's non-literal expressions using contextual information alone.

AS-students' use of metacognitive strategy use was one distinct finding, that is, they identified episodes of irony, sarcasm, metaphor and pun. One possible explanation as to why this may occur comes from a study by Whyte et al. (2013) 
who found that the understanding of irony increased slowly with age and that the older children in their study were better at making correct judgments about the speaker's intentions when they made ironic remarks. Interestingly, none of the ASstudents asked for clarification of the non-literal expressions used by their teachers. It is possible, they may have thought that identification of these types of figurative language constituted an understanding of them. However, it did seem that paraphrasing these types of non-literal expressions was also consistently more problematic for AS-students than NS.

The metacognitive strategy use by the AS-students leads us to considering ToM abilities, as ToM and WCC support the ability to read the intentions of others, and therefore interpretations of their messages. Happe (1993) found that the amount of ToM autistic individuals possessed would determine the amount of figurative language they could interpret. It would seem then, that the AS-students, in the present study, may still be developing ToM abilities for expressions that contain irony, sarcasm, metaphor and pun as demonstrated by their difficulty with inferring their teachers' intentions or perspectives. It may well be that the AS-students also had difficulty inferring what specific information the researcher needed to know to demonstrate their understanding of the expressions. For example, in the interview sessions, they (AS-students) may have felt that simply identifying a pun or irony was a sufficient answer and therefore did not see the need to provide any explanation. Put differently, it may have been more difficult for the AS-students than their neuro-typical peers to appreciate precisely what the researcher wanted from them. Still, while ToM is implicated and regarded as a core deficit in ASD (Martin \& McDonald, 2004), not every AS-student, as indicated in this study, demonstrated the same amount of ToM deficits in their interpretation of figurative expressions, therefore making it difficult to arrive at "neat and tidy" conclusions that ToM might be the most plausible explanation for student misinterpretation or paraphrasing difficulties. Other studies (Gernsbacher et.al, 2012; Whyte, 2012) suggest that syntax and vocabulary deficits are possible explanations for ASstudents' difficulties with expressing interpretations of figurative or non-literal expressions. While this study did not focus on vocabulary or syntactic abilities, per se, it may well be that these two areas did impact on the AS-students' difficulties with explaining the correct interpretations of their teachers' non-literal expressions. 
Another possibility for misinterpretation or lack of paraphrasing may be in the areas of organization and memory where the AS-students may have been unable to either organize information, or remember the contexts of the lessons as the interviews were retrospective.

Teachers were largely unaware of their use of non-literal expressions. This was similar to a study by Kerbel and Grunwell (1997) which focused on teachers' awareness of non-literal expressions with AS-students where teachers believed that they used fewer idioms with their students, both in special language units and in mainstream classrooms, than they actually did. Of note, and to be expected, unfamiliar expressions, vocabulary, and ambiguity in teacher expressions were a challenge for both AS-students and NS.

All teachers reported that they found the findings a useful opportunity to reflect on their communication with all students but with AS-students in particular, especially with the use of non-literal expressions. Not surprisingly, teachers with the least teaching experience were more surprised at the impact of their use of nonliteral expressions; teachers' comments included: 'I should be paying more attention to checking if they have understood those expressions in conversation and text comprehension"; "I should encourage the students to ask for clarification from me or their peers"; "I use too many instructions and too many sayings"; "it will be that word that got him; he clearly had trouble understanding that", "that word does have a double meaning", "Ahh he noticed that it might be a joke"; "good to see that they are understanding some of those expressions"; "she takes time to process the information so she may not get it", and "did I say that?"

\section{Concluding Comments}

Scholarship on autism has highlighted the tendency of AS-students to take figurative expressions literally, and so there were grounds for hypothesizing that adolescent students with AS in L1 classrooms may also experience interpretation problems when it comes to non-literal expressions. Therefore, the primary aim of this study was to find out to what extent (if at all) AS-students in mainstream secondary education experience difficulty interpreting their teachers' intended messages when these are conveyed through non-literal utterances. A secondary aim 
was to explore teachers' awareness about their non-literal language use with ASstudents (with L1 English) in high-school classrooms in New Zealand.

The findings indicated that the AS-students overall did not demonstrate understanding as well as their neuro-typical peers. It needs to be pointed out, however, that while this study's focus was to research AS-students' comprehension difficulties in the interpretation of non-literal expressions, it unearthed findings that pointed to AS-students' difficulties with paraphrasing/ explaining teacher expressions; the interpretation tasks may therefore to some degree be an artefact of the AS-students' offering less verbal evidence of understanding. Nevertheless, clear cases of misunderstanding - while relatively few in number - were found to be more typical of the AS-students. These mostly concerned utterances where the teachers used puns, novel metaphors, irony or sarcasm; the teachers were surprised at how little they did offer clarifications of these type of expressions to their students.

\subsection{Strategies to support students in the classroom}

The following suggestions for supporting AS-students' understanding and use of figurative language emanate from the findings of this study.

1) Teachers could engage in peer review/reflective practice by analyzing their classroom discourse for their use of non-literal expressions and incorporate more planned use to build students' understanding and explanations of them. This can be offered for example, through opportunities to regularly view video excerpts of classroom interactions where teachers and students can identify and explain non-literal expressions.

2) Interventions should include material that contains expressions incorporating irony, sarcasm, pun and metaphor, and other novel expressions. Teaching steps should include not only identification but paraphrasing of the meanings as steps to support non-literal interpretation. In addition, specific contexts in which they can be used and what they mean in situations must be included. One possible way that this can be done is to incorporate real-time discourse for students to view using video where they can identify and explain contextualized expressions and then discuss at how 
they were used in the situation in line with the intention of the speaker. However, it is necessary to provide the student with specific information, in small chunks to enable easier processing of the information.

3) Teachers should not only be aware of offering clarifications to their students but they should encourage students to ask for clarification as well. This can be done by providing a visual schedule or prompts that include planned asking to support the student to use this strategy rather than encouraging this incidentally only. For example, provide a flow chart that suggests options when they have difficulty interpreting text containing figurative language, and how to go about accessing those options (for example, look up an idiom dictionary or ask a teacher or peer).

4) When using visuals, ensure congruency between visual and oral cues when working with students who have processing difficulties and who have a tendency to interpret information literally.

5) Another useful strategy to help with interpretation and memory for conventional figurative meanings would be using the literal meaning of an expression to show how the figurative meaning can be derived from it. Boers and Lindstromberg (2012) suggests that this involves reminding learners of the literal meaning of the figurative use of an expression, so when the student encounters this word or expression (for example, 'bring someone up to speed', is a car analogy where accelerating while driving increases the speed to catch up/get someone to a place quickly). Boers and Lindstromberg (2005) also suggest that students can act out or draw these expressions which can aid students' memories of them. Overall, planned use of these strategies could have the simultaneous advantage of raising teachers' awareness of their use of non-literal expressions. For example, as seen in this study, the teacher who used the guinea pig analogy could identify this with students and explain its origins in laboratories. She may then become more be alerted to other such instances and therefore incorporate explanations or encourage clarification from the students. 


\section{Implications}

The implication from this study is that raising teachers' awareness of figurative language use in the classroom would be a welcome area of professional learning for high-school teachers to enhance academic and social outcomes for AS-students.

\section{Limitations and recommendations for further research}

A number of limitations need to be acknowledged in this study.

1) The small sample size means that results cannot be generalized. Further studies to broaden the findings are needed to facilitate the 'mainstreaming' of teachers' awareness of their use of non-literal expressions in classroom interactions thereby strengthening the interface between teaching and learning for students with a diagnosis of Asperger Syndrome. One way would be to repeat this study with more teachers and students and in different subject areas to add to or refute the findings of this study.

2) As the primary aim of this study was to find out to what extent (if at all) AS-students in mainstream secondary education experience difficulty interpreting their teachers' intended messages when these are conveyed through non-literal utterances, further research to determine the extent of teachers' use of non-literal expressions and AS-students' interpretation of them would establish a relationship between them. This would be conducted in a way similar to the study of Littlemore et al. (2011).

3) The pairing of AS-students with neuro-typical peers was far from wellcontrolled, that is, given the many other factors (including vocabulary knowledge, grammar abilities, etc.), we cannot consider the neurotypical peers truly 'matched controls' for the AS students. So, a battery of tests is recommended that incorporates non-verbal abilities, grammar and vocabulary to match controls with more rigour.

4) It would be important to conduct studies beyond the controlled interview situation to determine if AS-students' responses to non-literal expressions in more real/social environments would reveal more or fewer misunderstandings than the controlled environment. One way to 
do this would be to video or audiotape "natural" interactions between AS-students and their teachers/ peers in extended discourse activities/lessons. 


\section{References}

Abrahamsen, E. P., \& Smith, R. (2000). Facilitating idiom acquisition in children with communication disorders: Computer vs classroom. Child Language Teaching and Therapy, 16(3), 227-239.

Attwood, T. (2006). The complete guide to Asperger's syndrome. London: Jessica Kingsley Publishers.

Autism New Zealand (n.d.) About Autism Retrieved from https://www.autismnz.org.nz/about autism

Bardovi-Harlig, K., (2012). Formulas, routines, and conventional expressions in pragmatics research. Annual Review of Applied Linguistics, 32, 206-227. doi: $10.1017 / \mathrm{S} 0267190512000086$

Baron-Cohen, S. (1997). Mindblindness: An essay on autism and theory of mind. Cambridge, MA: MIT Press.

Boers, F., \& Lindstromberg, S. (2005). Finding ways to make phrase-learning feasible: The mnemonic effect of alliteration. System, 33(2), 225-238.

Boers, F., J. Eyckmans \& H. Stengers (2007) Presenting figurative idioms with a touch of etymology: More than mere mnemonics? Language Teaching Research 11(1): 43-62.

Boers, F., \& Lindstromberg, S. (2012). Experimental and Intervention Studies on Formulaic Sequences in a Second Language. Annual Review of Applied Linguistics, 32, 83-110

Bremer, K. (1996). Causes of understanding problems. In K. Bremer, C. Roberts, M.T.

Vasseur, M. Simonot, \& P. Broeder (Eds.), Achieving understanding. Discourse in intercultural encounters (pp. 40). London: Longman.

Cameron, L. (2003). Metaphor in educational discourse. London: Continuum.

Castelli, F., Frith, C., Happé, F., \& Frith, U. (2002). Autism, Asperger syndrome and brain mechanisms for the attribution of mental states to animated shapes. Brain, 125(8), 1839-1849.

Church, C., Alisanski, S., \& Amanullah, S. (2000). The social, behavioral, and academic experiences of children with Asperger syndrome. Focus on Autism and Other Developmental Disabilities, 15(1), 12-20.

Colston, H. L., \& Kuiper, M. S. (2002). Figurative language development research and popular children's literature: Why we should know, "Where the wild things are". Metaphor and Symbol, 17(1), 27-43.

doi:10.1207/S15327868MS1701_3 
Dennis, M., Lazenby, A. L., \& Lockyer, L. (2001). Inferential language in highfunction children with autism. Journal of Autism and Developmental Disorders, 31(1), 47-54.

Ezell, H. K., \& Goldstein, H. (1992). Teaching idiom comprehension to children with mental retardation. Journal of Applied Behavior Analysis, 25(1), 181191.

Frith, U. (1989) Autism: Explaining the enigma. Oxford: Blackwell

Frith, U., \& Happé, F. (1994). Autism: beyond "theory of mind". Cognition, 50(1), 115-132.

Gernsbacher, M. A., \& Pripas-Kapit, S. R. (2012). Who's missing the point? A commentary on claims that autistic persons have a specific deficit in figurative language comprehension, Metaphor and Symbol, 27, 93-105.

Giora, R. (1997). Understanding figurative and literal language: The graded salience hypothesis. Cognitive Linguistics, 8(3), 183-206.

Granger, S. (1998). Prefabricated patterns in advanced EFL writing: Collocations and lexical phrases. In A. Cowie (Ed.), Phraseology: Theory, analysis and applications (pp. 145-160). Oxford: Oxford University Press.

Happé, F. (1993). Communicative competence and theory of mind in autism: A test of Relevance theory. Cognition, 48,101-119.

Happé, F. (1994). An advanced test of theory of mind: Understanding of story characters' thoughts and feelings by able autistic, mentally handicapped, and normal children and adults. Journal of Autism and Developmental disorders, 24(2), 129-154.

Happé, F., \& Frith, U. (2006). The weak coherence account: detail-focused cognitive style in autism spectrum disorders. Journal of Autism and Developmental Disorders, 36(1), 5-25.

Howarth, P. (1998). The phraseology of learners' academic writing. In A. Cowie (Ed.), Phraseology: Theory, analysis and applications (pp. 161-86). Oxford: Oxford University Press.

Jarrold, C., Butler, D., Cottington, E., \& Jiminez, F. (2000). Linking Theory of Mind and central coherence bias in autism and the general population. Developmental Psychology, 36(1), 126-138.

Jolliffe T, \& Baron-Cohen, S. (2000) Linguistic processing in high-functioning adults with autism or Asperger syndrome: Can global coherence be achieved? A further test of central coherence theory. Psychological Medicine, 30(5), 1169-118. 
Kana, R. K., \& Wadsworth, H. M. (2012). 'The archeologist's career ended in ruins': Hemispheric differences in pun comprehension in autism. NeuroImage, 62(1), 77-86.

Kerbel, D., \& Grunwell, P. (1997). Idioms in the classroom: An investigation of language unit and mainstream teachers' use of idioms. Child Language Teaching and Therapy, 13(2), 113-123.

Kövecses, Z. (2011). Recent developments in metaphor theory: Are the new views rival ones?. Review Of Cognitive Linguistics, 9(1), 11-25. doi:10.1075/ml.9.1.02kov

Lakoff, G., \& Johnson, M. (1980). Metaphors we live by. Chicago: University of Chicago Press.

Lanter, E., \& Watson, L. R. (2008). Promoting literacy in students with ASD: The basics for the SLP. Language, Speech, and Hearing Services in Schools, 39(1), 33-43.

Lazar, R. T., Warr-Leeper, G. A., Nicholson, C. B., \& Johnson, S. (1989). Elementary school teachers' use of multiple meaning expressions. Language, Speech, and Hearing Services in Schools, 20(4), 420-430.

Littlemore, J., Chen, P. T., Koester, A., \& Barnden, J. (2011). Difficulties in metaphor comprehension faced by international students whose first language is not English. Applied Linguistics, 32(4), 408-429.

Martin, I., \& McDonald, S. (2004). An exploration of causes of non-literal language problems in individuals with Asperger Syndrome. Journal of Autism and Developmental Disorders, 34(3), 311-328.

Martinez, R., \& Murphy, V. A. (2011). Effect of frequency and idiomaticity on second language reading comprehension. TESOL Quarterly, 45(2), 267-290.

Mason, R. A., Williams, D. L., Kana, R. K., Minshew, N., \& Just, M. A. (2008). Theory of mind disruption and recruitment of the right hemisphere during narrative comprehension in autism. Neuropsychologia, 46(1), 269-280.

Mercer, K. L. (2009). Understanding the literacy difficulties of students with Asperger's Syndrome in middle years' classrooms. Literacy Learning: The Middle Years, 17(2), 11-21.

Minshew, N. J., Goldstein, G. (1998). Autism as a disorder of complex information processing. Mental Retardation and Developmental Disabilities Research Reviews, 4(2), 129-136.

Mitchell, P., Saltmarsh, R., \& Russell, H. (1997). Overly literal interpretations of speech in autism: Understanding that messages arise from minds. Journal of Child Psychology and Psychiatry, 38(6), 685-691. 
Moirón, B. V., \& Tiedemann, J. (2006). Identifying idiomatic expressions using automatic word-alignment. Retrieved from http://aclarc.comp.nus.edu.sg/archives/acl-arc-090501d4/data/pdf/anthologyPDF/W/W06/W06-2405.pdf

Nippold, M. A. (1991). Evaluating and enhancing idiom comprehension in language-disordered students. Language, Speech, and Hearing Services in Schools, 22(3), 100-106.

Nippold, M. A., \& Martin, S. T. (1989). Idiom interpretation in isolation versus context: A developmental study with adolescents. Journal of Speech, Language, and Hearing Research, 32(1), 59-66.

Norbet, S. (2013). Formulaic Language and Collocation. In C. A. Chapelle (Ed.), The Encyclopedia of Applied Linguistics (pp. 1-9). New York: Blackwell. doi:10.1002/9781405198431.wbeal0433

Norbury, C. F. (2004). Factors Supporting Idiom Comprehension in Children with Communication Disorders. Journal of Speech, Language, and Hearing Research, 47(5), 1179.

O'Connor, I., \& Klein, P. (2004). Exploration of strategies for facilitating the reading comprehension of high-functioning students with autism spectrum disorders. Journal of Autism \& Developmental Disorders, 34(2), 115-127.

Pragglejaz Group (2007). MIP: A method for identifying metaphorically used words in discourse. Metaphor and symbol, 22(1), 1-39.

Qualls, C. D., Lantz, J. M., Pietrzyk, R. M., Blood, G. W., \& Hammer, C. S. (2004). Comprehension of idioms in adolescents with language-based learning disabilities compared to their typically developing peers. Journal of Communication Disorders, 37, 295-311. doi:10.1016/j.jcomdis.2003.12.001

Rapp, A. M., Mutschler, D. E., \& Erb, M. (2012). Where in the brain is nonliteral language? A coordinate-based meta-analysis of functional magnetic resonance imaging studies. Neuroimage, 63(1), 600-610.

Rundblad, G., \& Annaz, D. (2010). The atypical development of metaphor and metonymy comprehension in children with autism. Autism, 14(1), 29-46.

Samuels, S. J. (1970). Effects of pictures on learning to read, comprehension, and attitudes. Review of Educational Research, 40, 397-407.

Swinney, D. A., \& Cutler, A. (1979). The access and processing of idiomatic expressions. Journal of Verbal Learning and Verbal Behavior, 18(5), 523534. 
Szatmari, P., Tuff, L., Finlayson, M. A. J., \& Bartolucci, G. (1990). Asperger's syndrome and autism: Neurocognitive aspects. Journal of the American Academy of Child \& Adolescent Psychiatry, 29(1), 130-136.

Titone, D. A., \& Connine, C. M. (1994). Descriptive norms for 171 idiomatic expressions: Familiarity, compositionality, predictability, and literality. Metaphor and Symbolic Activity, 9(4), 247-70.

Vulchanova, M., Saldaña, D., Chahboun, S., \& Vulchanov, V. (2015). Figurative language processing in atypical populations: the ASD perspective. Frontiers in human neuroscience, 9, 1-11.

Vogindroukas, I., \& Zikopoulou, O. (2011). Idiom understanding in people with Asperger syndrome/high functioning autism. Revista da Sociedade Brasileira de Fonoaudiologia, 16(4), 390-395.

Wang, A. T., Lee, S.S., Sigman, M., \& Dapretto, M. (2006). Neural basis of irony comprehension in children with autism: The role of prosody and context. Brain, 129, 932-943.

Warren, B., \& Erman, B. (2000). The idiom principle and the open choice principle. Text, 20(1), 29-62.

Webb, S., Newton, J., \& Chang, A. C. S. (2013). Incidental learning of collocation. Language Learning, 63, 91-120.

Whyte, E. M. (2012). Predictors of figurative and pragmatic language comprehension in children with autism and typical development (Doctoral dissertation, The Pennsylvania State University).

Whyte, E. M., Nelson, K. E., \& Khan, K. S. (2013). Learning of idiomatic language expressions in a group intervention for children with autism. Autism, 17(4), 449-464.

Wray, A. (2012). What do we (think we) know about formulaic language? An evaluation of the current state of play. Annual Review of Applied Linguistics, $32,231-254$. 


\section{Appendices}


School information sheet

School of Linguistics and Applied Language Studies

Victoria University

P.O. Box 600

Wellington

New Zealand

+6444635600

Information Sheet:

High school teachers' use of language in classroom interactions

Do all students understand the same message?

\section{Researcher: Muno Richards School of Linguistics and Applied Language Studies, Victoria University of Wellington}

Kia Ora (Name)

I am a Master's candidate in Applied Linguistics at Victoria University in Wellington with a professional background in speech-language therapy. As part of this degree I am researching teachers' awareness and knowledge about their language use with students in high school classrooms in NZ. In particular, as a professional speech-language therapist, I am interested to see how students with differing abilities interpret teacher expressions used in daily classroom interactions.

I would appreciate the participation in this research project of year 9 and 10 teachers and their students involved in English and Social Studies. The teachers and students need to have English as their first language.

Participation involves me observing teachers in their classes, at least 2 lessons, and collecting a sample of their language using audio and video recording equipment. These observations will be up to 60 minutes per lesson. The samples will provide data that will be presented to two groups of students: one group will be students who have been diagnosed with Aspergers Syndrome and the other group will be neurotypical peers of the same age. Students will be asked to tell me or write down their interpretations of the expressions identified in the sample of teachers' language that I collected in the classes. This task time is around 30-40 minutes and will need to be during school-time. I will also need to ask your Special Education Needs Coordinators to contact parents whose children have been diagnosed with Aspergers Syndrome to seek their interest and participation in my research. am seeking permission from you to access the students' records/assessments of their speaking, reading and writing levels to make sure that I communicate with them at their level and to ensure that all the students who take part in the research are at a similar level. Their responses in my research task are not related to any school 
assessment /achievement data. The teachers will also be interviewed at a time and place suitable to them, at school and after school hours. Students will be provided with a canteen voucher for their participation (suggestions will be discussed with you in line with your school policy) and teachers will be given a box of chocolates for their participation. In addition, teachers will have an opportunity to reflect on their language use in the classroom.

Information collected in this study will remain confidential and will only serve research purposes. The findings will be reported in a thesis, which will be submitted to the School of Linguistics and Applied Language Studies, and may later be published in an academic or professional journal and/or disseminated at an academic or professional conference. This research project has received approval from the Victoria University Human Ethics Committee. If you have concerns about ethical aspects of this research project or if you have any questions about the Human Ethics Committee and its role, contact Associate Professor Susan Corbett, email susan.corbett@vuw.ac.nz, telephone +64-4-463 5480.

You are welcome to contact my supervisor, Associate Professor Frank Boers from the School of Linguistics and Applied Language Studies, Victoria University of Wellington, PO Box 600, Wellington 6140, New Zealand, or via email: frank.boers@vuw.ac.nz, or phone +64 44636014 or myself : muno.richards@vuw.ac.nz

Thank you for permission to access the contributions of your staff and students.

Muno Richards 
School of Linguistics and Applied Language Studies

Victoria University

P.O. Box 600

Wellington

New Zealand

+6444635600

\section{Parent Information Sheet:}

High school teachers' use of language in classroom interactions

Do all students understand the same message?

Researcher: Muno Richards School of Linguistics and Applied Language Studies, Victoria University of Wellington

Appropriate greeting/ (Name)

I am a Master's candidate in Applied Linguistics at Victoria University in Wellington with a professional background in speech-language therapy. As part of this degree I am researching teachers' awareness and knowledge about their language use with students in high school classrooms in NZ. In particular, as a professional speech-language therapist, I am interested to see how students with differing abilities interpret teachers' use of language in daily classroom interactions. I have particular expertise and over 20 years of experience in supporting children and young people who have been diagnosed with Autism, and their families. Your school principal has been informed of this research.

Your school principal has been informed of this research.

I would value the participation of your child in this research project. It involves me observing and audio-recording English and Social Studies lessons to collect samples of the language used in the classroom. I would like to observe at least 2 lessons of up to 60 minutes per lesson. From these observations and recordings, I will extract samples of language used by the teachers. These samples will be used later on as prompts in interviews with the students which will take place in a meeting room at the school. Students will be asked to tell me or write down their interpretations of the language I heard their teachers' use in the classes. This task is expected to take around 30 minutes and will be during school time. I am seeking permission from you to see your child's records/assessments of their speaking, reading and writing levels to make sure that I communicate with them at their level and that all the students who take part in the research are at a similar level. Their responses in my research task are not related to any school assessment 
/achievement data and will not affect their school grades. You are welcome to participate as an observer or support person for your child during the interview where I ask him/her to tell me their interpretation of their teacher's expressions. I have also enclosed an information sheet for you to share with your child. I will be offering your child a voucher to spend at the school canteen as a thank you for their participation in the research project.

The data I collect from the above means will form the basis of my research project and will be put into a written report. It will not be possible for you or your child to be identified personally in that report or in any other communication of the research findings. All material collected will be kept confidential.

Should you feel the need to withdraw your child from the project, you can do so at any time before 16 September 2016. You may withdraw by emailing me at the address I have provided at the end of this information sheet. If you decide to withdraw, I will return all interview data, notes, and recordings and will not refer to these sources in my thesis. This thesis will be submitted to the School of Linguistics and Applied Language Studies. In addition, the findings may be reported - again without disclosing any participant's identity - in an academic or professional journal and/or at an academic or professional conference.

The research project has received approval from the Victoria University Human Ethics Committee. If you have concerns about ethical aspects of this research project or if you have any questions about the Human Ethics Committee and its role, contact Associate Professor Susan Corbett, email susan.corbett@vuw.ac.nz, telephone +64-4-463 5480 .

You are welcome to contact my supervisor, Associate Professor Frank Boers from the School of Linguistics and Applied Language Studies, Victoria University of Wellington, PO Box 600, Wellington 6140, New Zealand, or via email: frank.boers@vuw.ac.nz, or phone +64 44636014 or myself : muno.richards@vuw.ac.nz.

Thank you so much for your assistance with this research project.

Muno Richards 
Parent information sheet (for neuro-typical students)

School of Linguistics and Applied Language Studies

Victoria University

P.O. Box 600

Wellington

New Zealand

+6444635600

\section{Parent Information Sheet:}

High school teachers' use of language in classroom interactions Do all students understand the same message?

Researcher: Muno Richards School of Linguistics and Applied Language Studies, Victoria University of Wellington

Appropriate greeting/ (Name)

I am a Master's candidate in Applied Linguistics at Victoria University in Wellington with a professional background in speech-language therapy. As part of this degree I am researching teachers' awareness and knowledge about their language use with students in high school classrooms in NZ. In particular, as a professional speech-language therapist, I am interested to see how students with differing abilities interpret teachers' use of language in daily classroom interactions. Your school principal has been informed of this research.

I would value the participation of your child in this research project. It involves me observing and audio-recording English and Social Studies lessons to collect samples of the language used in the classroom. I would like to observe at least 2 lessons of up to 60 minutes per lesson. From these observations and recordings, I will extract samples of language used by the teachers. These samples will be used later on as prompts in interviews with the students which will take place in a meeting room at the school. Students will be asked to tell me or write down their interpretations of the language I heard their teachers' use in the classes. This task is expected to take around 30 minutes and will be during school time. I am seeking permission from you to see your child's records/assessments of their speaking, reading and writing levels to make sure that I communicate with them at their level and that all the students who take part in the research are at a similar level. Their responses in my research task are not related to any school assessment /achievement data and will not affect their school grades. You are welcome to participate as an observer or support person for your child during the interview where I ask him/her to 
tell me their interpretation of their teacher's expressions. I have also enclosed an information sheet for you to share with your child. I will be offering your child a voucher to spend at the school canteen as a thank you for their participation in the research project.

The data I collect from the above means will form the basis of my research project and will be put into a written report. It will not be possible for you or your child to be identified personally in that report or in any other communication of the research findings. All material collected will be kept confidential.

Should you feel the need to withdraw your child from the project, you can do so at any time before 16 September 2016. You may withdraw by emailing me at the address I have provided at the end of this information sheet. If you decide to withdraw, I will return all interview data, notes, and recordings and will not refer to these sources in my thesis. This thesis will be submitted to the School of Linguistics and Applied Language Studies. In addition, the findings may be reported - again without disclosing any participant's identity - in an academic or professional journal and/or at an academic or professional conference.

The research project has received approval from the Victoria University Human Ethics Committee. If you have concerns about ethical aspects of this research project or if you have any questions about the Human Ethics Committee and its role, contact Associate Professor Susan Corbett, email susan.corbett@vuw.ac.nz, telephone +64-4-463 5480.

You are welcome to contact my supervisor, Associate Professor Frank Boers from the School of Linguistics and Applied Language Studies, Victoria University of Wellington, PO Box 600, Wellington 6140, New Zealand, or via email: frank.boers@vuw.ac.nz, or phone +64 44636014 or myself : muno.richards@vuw.ac.nz.

Thank you so much for your assistance with this research project.

Muno Richards 
Student information sheet

Information Sheet for Students:

Topic: High school teachers' use of language in classroom interactions Do all students understand the same message?

\section{Researcher: Muno Richards, School of Linguistics and Applied Language Studies, Victoria University of Wellington}

$\mathrm{Hi}$, my name is Muno Richards. I am a speech-language therapist and I work in different schools in New Zealand. I am doing research about the words and expressions teachers use during class time as part of my study at Victoria University of Wellington.

I have asked you to help me because I want to know how you understand what your teacher says in class. This research is important because the findings may help teachers adjust their use of language to ensure the students understand their lessons.

I am going to visit the class during English and Social Studies and I will listen to the language that is used in the classroom by the teacher and the students. I will use audio recordings so I can re-listen to the lesson after I have visited the classroom.

I will have a meeting with you in a room at school. During this meeting I will give you a sheet with some words and sentences that I heard in your classroom when I visited. I will ask you to tell me what you think the teacher meant when she or he used those words or sentences. This will take no more than 30 minutes. There will be no 'right' or 'wrong' answers. I am only interested to know what you think your teacher meant. You can either write down your answers or just tell me your answers. In the latter case, I will record your answers on audiotape. We will have a short practice run before you start the actual activity. I will also show you a video to demonstrate what is expected of you.

Nothing I hear you say in class nor any of your answers to my questions will affect your school marks or grades.

You can have a teacher /mum/dad/friend with you when you are writing or talking about the words and sentences on the worksheet. They will not help you, but just sit with you in the room. You can also have a break during the meeting at any time. At the end of the meeting I will give you a voucher to buy something from the canteen.

All the recordings and all your answers to my questions will be listened to or looked at only by me and my supervisor (my helper in this research) at 
my university. When I write up the findings of this research project or present the findings to other researchers, I will make sure that all personal details (your name, etc.) are removed.

You and your parents can ask for a general summary of what I have found about teachers' use of language in the classroom and how it is understood by their students.

If you agree to take part in this research project, but change your mind later on, then you can do so. All you need to do is tell me or ask your parent to tell me (my contact details are below). But, if you wish to withdraw your information from the research project, then please do so before 16 September 2016. Otherwise it will be very difficult for make the changes in my report before I submit it to my university.

This research project has received approval from the Victoria University Human Ethics Committee. If you have questions about ethical aspects of this research project or if you have any questions about the Human Ethics Committee and its role, contact Associate Professor Susan Corbett, email susan.corbett@vuw.ac.nz, telephone +64-4-463 5480.

You are welcome to contact my supervisor, Associate Professor Frank Boers from the School of Linguistics and Applied Language Studies, Victoria University of Wellington, PO Box 600, Wellington 6140, New Zealand, or via email: frank.boers@vuw.ac.nz, or phone +64 44636014 or myself : muno.richards@vuw.ac.nz.

Thank you very much for helping me.

Muno Richards 